\title{
Effects of taphonomic deformation on geometric morphometric analysis of fossils: a study using the dicynodont Diictodon feliceps (Therapsida, Anomodontia)
}

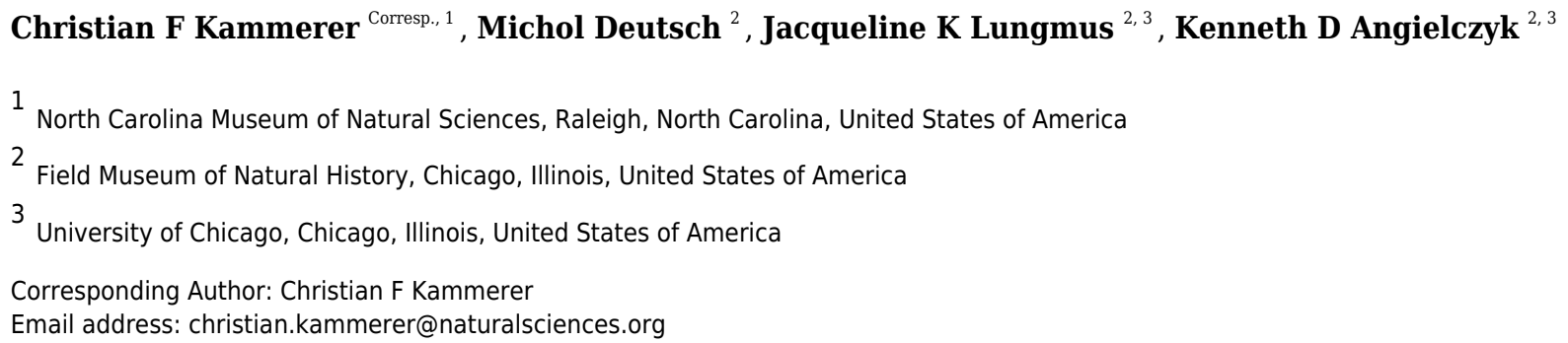

Taphonomic deformation, the distortion of fossils as a result of geological processes, poses problems for the use of geometric morphometrics in addressing paleobiological questions. Signal from biological variation, such as ontogenetic trends and sexual dimorphism, may be lost if variation from deformation is too high. Here, we investigate the effects of taphonomic deformation on geometric morphometric analyses of the abundant, well known Permian therapsid Diictodon feliceps. Distorted Diictodon crania can be categorized into seven typical styles of deformation: lateral compression, dorsoventral compression, anteroposterior compression, 'saddle-shape' deformation (localized collapse at cranial midlength), anterodorsal shear, anteroventral shear, and right/left shear. In simulated morphometric datasets incorporating known 'biological' signals and subjected to uniform shear, deformation was typically the main source of variance but accurate 'biological' information could be recovered in most cases. However, in empirical datasets, not only was deformation the dominant source of variance, but little structure associated with allometry and sexual dimorphism was apparent, suggesting that the more varied deformation styles suffered by actual fossils overprint biological variation. In a principal component analysis of all anomodont therapsids, deformed Diictodon specimens exhibit significant dispersion around the 'true' position of this taxon in morphospace based on undistorted specimens. The overall variance associated with deformation for Anomodontia as a whole is minor, and the major axes of variation in the study sample show a strong phylogenetic signal instead. Although extremely problematic for studying variation in fossil taxa at lower taxonomic levels, the cumulative effects of deformation in this study are shown to be random, and inclusion of deformed specimens in higher-level analyses of morphological disparity are warranted. Mean morphologies of distorted specimens are found to approximate the morphology of undistorted specimens, so we recommend use of 
species-level means in higher-level analyses when possible. 


\section{Effects of taphonomic deformation on geometric morphometric analysis of}

2 fossils: a study using the dicynodont Diictodon feliceps (Therapsida,

\section{Anomodontia)}

5 Christian F. Kammerer ${ }^{1}$, Michol Deutsch ${ }^{2}$, Jacqueline K. Lungmus ${ }^{2,3}$, Kenneth D. Angielczyk ${ }^{2,3}$

$7 \quad{ }^{1}$ North Carolina Museum of Natural Sciences, Raleigh, North Carolina, United States of America

$8 \quad$ Field Museum of Natural History, Chicago, Illinois, United States of America

$9 \quad{ }^{3}$ University of Chicago, Chicago, Illinois, United States of America

11 Corresponding author: Christian F. Kammerer, christian.kammerer@naturalsciences.org

\section{ABSTRACT}

14 Taphonomic deformation, the distortion of fossils as a result of geological processes, poses

15 problems for the use of geometric morphometrics in addressing paleobiological questions. Signal

16 from biological variation, such as ontogenetic trends and sexual dimorphism, may be lost if

17 variation from deformation is too high. Here, we investigate the effects of taphonomic

18 deformation on geometric morphometric analyses of the abundant, well known Permian

19 therapsid Diictodon feliceps. Distorted Diictodon crania can be categorized into seven typical

20 styles of deformation: lateral compression, dorsoventral compression, anteroposterior

21 compression, 'saddle-shape' deformation (localized collapse at cranial mid-length), anterodorsal

22 shear, anteroventral shear, and right/left shear. In simulated morphometric datasets incorporating

23 known 'biological' signals and subjected to uniform shear, deformation was typically the main 
24 source of variance but accurate 'biological' information could be recovered in most cases.

25 However, in empirical datasets, not only was deformation the dominant source of variance, but

26 little structure associated with allometry and sexual dimorphism was apparent, suggesting that

27 the more varied deformation styles suffered by actual fossils overprint biological variation. In a

28 principal component analysis of all anomodont therapsids, deformed Diictodon specimens

29 exhibit significant dispersion around the 'true' position of this taxon in morphospace based on

30 undistorted specimens. The overall variance associated with deformation for Anomodontia as a

31 whole is minor, and the major axes of variation in the study sample show a strong phylogenetic

32 signal instead. Although extremely problematic for studying variation in fossil taxa at lower

33 taxonomic levels, the cumulative effects of deformation in this study are shown to be random,

34 and inclusion of deformed specimens in higher-level analyses of morphological disparity are

35 warranted. Mean morphologies of distorted specimens are found to approximate the morphology

36 of undistorted specimens, so we recommend use of species-level means in higher-level analyses

37 when possible.

38 Subjects: Evolutionary Studies, Paleontology, Zoology

39 Keywords: Taphonomy; morphometrics; Synapsida; Dicynodontia; Permian; simulations 


\section{INTRODUCTION}

42 Geometric morphometrics is a well-established tool for addressing biological questions related to shape (Bookstein, 1991; Zelditch et al., 2004). The discriminatory power of geometric morphometrics allows for fine-scale resolution of shape differences between organisms or their parts. Although initially developed in the study of extant organisms, geometric morphometrics has also been used extensively to study fossil taxa, including representatives of all major vertebrate groups (e.g., Botha \& Angielczyk, 2007; Deeming \& Mayr, 2018; Pérez-Ben, Báez \& Schoch, 2019; Price et al., 2019; Felice et al., 2019). These techniques have been used for biomechanical modeling (e.g., Pierce, Angielczyk \& Rayfield, 2008; Polly et al., 2016) and to quantify the evolution of morphological disparity (e.g., Brusatte et al., 2012; Lungmus \& Angielczyk, 2019), evolutionary rate (e.g., Adams, 2014), and ecological adaptions (e.g., Grossnickle \& Newham, 2016). However, in contrast to extant systems, where the effects of biased sampling can be easily controlled, geometric morphometric studies on fossils include an additional, abiotic source of morphological variation: that of taphonomic deformation. the surrounding rock (Angielczyk \& Sheets, 2007). Although taphonomic deformation of fossils can provide useful information in a geological context (Ramsay \& Huber, 1983), in the field of paleobiology it is a problematic source of error, obscuring biologically important characteristics of fossil organisms. Various retrodeformation methods have been proposed to quantify and correct distortion in fossils (e.g., Wellman, 1962; Hughes \& Jell, 1992; Rushton \& Smith, 1993; 
63 2014; Lautenschlager, 2016), but tests have shown that these techniques do not always recover

64 underlying biological variance in specimens of known original morphology (Angielczyk \&

65 Sheets, 2007; Tschopp, Russo \& Dzemski, 2013; Schlager et al., 2018). Given this problem, and

66 the substantial practical difficulties involved in the retrodeformation of large sample sizes, a

67 better understanding of the effects of taphonomic variation on biological variance in fossils is 68 desirable.

For geometric morphometric analyses in particular, it is currently uncertain to what degree taphonomic deformation can 'overwrite' the underlying signal of biological shape variation. Does distortion obscure variation intraspecifically, interspecifically, or even at higher clade levels? To address these questions, study systems comprising taxa represented by large sample sizes known from a variety of localities and stratigraphic intervals are needed. Although a frequent target for morphometric and other disparity-based analyses, few groups of terrestrial vertebrates satisfy these criteria. A noteworthy exception, however, can be found in the nonmammalian Synapsida.

Non-mammalian synapsids are one of the major groups of Paleozoic terrestrial vertebrates, and dominated ecosystems in both abundance and richness from the Pennsylvanian through the Middle Triassic (Kemp, 1982; Rubidge \& Sidor, 2001; Angielczyk \& Kammerer, 2018). Non-mammalian synapsids have a rich fossil record, especially in the biostratigraphically well-resolved Beaufort Group of South Africa, which preserves a nearly continuous record of vertebrate fossils from the middle Permian through the Middle Triassic (Rubidge, 1995, 2005; Smith, Rubidge \& van der Walt, 2012; Rubidge et al., 2016). The period of time in which nonmammalian synapsids were dominant encompasses several major biotic events in Earth history, 
86 mass extinction (Ward et al., 2000, 2005; Smith \& Botha-Brink, 2014). Given the plentiful

87 available specimens, heavily sampled faunal assemblages, lengthy evolutionary history, and

88 wide variety of inferred ecologies (Kemp, 1982) in non-mammalian synapsids, this group

89 represents an ideal system in which to study morphospace occupation and disparity over time

90 (Kammerer, 2009).

$91 \quad$ Although a number of synapsid species are represented by large sample sizes ranging

92 into the hundreds of specimens (Smith et al., 2012; Codron et al., 2017), the group also includes

93 numerous stratigraphically and phylogenetically important species represented by very few

94 individuals (e.g., all but one species in the therapsid subclade Burnetiamorpha are known from a

95 single skull; Sidor, 2015; Day et al., 2018). Ideally, analyses of synapsid morphological disparity

96 should include both abundant taxa as well as rare species. Of concern, however, are the possible

97 effects deformation may have on morphospace occupation across taxa with varying sample sizes.

98 A singleton taxon known only from a highly distorted specimen will to some degree be displaced

99 from its 'true' position in morphospace, with the associated degree of error unknowable pending

100 discovery of new, undistorted specimens (though it can be roughly estimated using

101 retrodeformation in some cases). The likelihood of preserving undistorted specimens is higher in

102 an abundant taxon, which can also provide the means to quantify the amount of error incurred

103 through the inclusion of distorted specimens in morphometric analyses. However, samples of an

104 abundant fossil taxon carry their own problems. Abundant taxa, especially those with wide

105 geographic and stratigraphic ranges, are more likely to exhibit a broader range of styles of

106 deformation than specimens of a rare one. A distorted singleton can only be displaced from its

107 'true' position in morphospace unidirectionally, but numerous specimens distorted in different

108 ways may disperse from their 'true' position in a variety of directions to varying degrees 
109 (Angielczyk \& Sheets, 2017; Hedrick et al., 2019). In a specimen-level morphometric analysis,

110 increased dispersion of distorted individuals around their 'true' position in morphospace may

111 artificially inflate some disparity metrics (e.g., total morphospace occupation of a taxon/clade).

112 Alternatively (and possibly concurrently), a widely dispersed cluster of distorted specimens of an

113 abundant taxon relative to rare ones may result in the underestimation of distance-based

114 measures of disparity (with taxon-to-taxon distance in morphospace artificially reduced by

115 distorted specimens of one taxon impinging on the 'true' morphospace of another). This issue

116 can also confound use of morphometric analysis for taxon discrimination, if specimens of a rare

117 but biologically distinct taxon fall within the inflated specimen cloud of an abundant taxon due

118 to distortion in the latter. A final, most distressing possibility is that high levels of deformation in

119 abundant taxa completely overwhelm underlying biological variance in the study group, resulting

120 in a morphospace that summarizes abiotic distinctions between individuals rather than any

121 biologically meaningful variables.

122

Given these potential difficulties, it is important to address certain questions regarding

123 taphonomic deformation in morphometric studies, focusing here on the synapsid fossil record as

124 a case study. For example, is deformation of synapsid specimens random, and if not, does the

125 directionality of deformation change with geographic and/or stratigraphic position? Do deformed

126 specimens alter the structure of morphospace within groups and/or between groups? Does the

127 inclusion of numerous deformed specimens significantly alter measures of disparity in a study

128 group? Is biological variability overwhelmed by taphonomic variability, and if so, at what

129 taxonomic levels? 
131 analyses centered on the abundant dicynodont therapsid Diictodon feliceps. We have four main

132 objectives:

133 1. Description of the major forms of deformation in the cranium of Diictodon. The range of

134 variation attributable to deformation in Diictodon crania will be described and the possible

135 effects of this deformation on morphometric analysis discussed.

136 2. Test the effects of deformation on intraspecific morphospace analyses. An empirical

137 morphospace for Diictodon will be constructed using the results of a principal components

138 analysis of cranial landmark data, and variation in this morphospace as related to biological and

139 deformational variables will be examined. The null hypotheses are that deformation is random

140 and that random deformation adds noise to the data but does not overwhelm known biological

141 signals.

142 3. Use simulations featuring known types and amounts of deformation to investigate the

143 circumstances when deformation is likely overwhelming our ability to extract biological signal

144 from a dataset. We will focus on correctly recovering signals reflecting ontogenetic variation and

145 sexual dimorphism (well-supported sources of morphological variability in actual Diictodon

146 fossils; Sullivan \& Reisz, 2005). Of particular interest is whether an accurate signal is preserved

147 in simulated datasets displaying levels of variance comparable to the empirical dataset.

148 4. Test the effects of deformation on morphospace analyses at higher taxonomic levels. Samples

149 of deformed and undistorted Diictodon specimens will be included in a broad-scale morphospace

150 analysis of Anomodontia, the larger clade to which dicynodonts belong, to determine whether

151 the addition of deformed specimens alters the primary variance structure of the dataset. The

152 overall disparity in the anomodont sample with and without the deformed Diictodon specimens 
153 will be compared. The null hypotheses are that deformation is random and that random

154 deformation in one taxon (Diictodon) does not overwhelm interspecific sources of morphological

155 variance. We will compare the results of this empirical study to cases in which simulated

156 specimens with known amounts and types of deformation are added to an anomodont-wide 157 dataset.

MATERIALS AND METHODS

\section{Study system}

162 The Permian dicynodont Diictodon feliceps (Owen, 1876) is a long-ranging species known

163 predominantly from the Karoo Basin of South Africa, although it has also been found in Zambia 164 and China (Angielczyk \& Sullivan, 2008; Angielczyk et al., 2014). This species is useful for 165 investigating the effects of deformation in the context of geometric morphometric analysis for 166 several reasons. First, Diictodon is the most abundant terrestrial vertebrate known from the

167 Beaufort Group (Smith et al. 2012), making up more than 50\% of vertebrate fossils from some

168 localities (Smith, 1993; Sidor \& Smith, 2007; Brocklehurst et al., 2017; Day \& Rubidge, 2019).

169 Second, the long stratigraphic range of Diictodon (covering five of the eight Beaufort Group

170 assemblage zones, Capitanian to Changhsingian) offers the opportunity to address the potential

171 problem of changing styles of deformation as a result of changes in the sedimentary geology of

172 the Karoo Basin over the course of the Permian (Smith, 1995; Tankard et al., 2009; Barbolini et

173 al., 2016). Third, the sample of South African Diictodon specimens exhibits clear underlying

174 biological variation. Sullivan et al. (2003) demonstrated readily recognizable sexual dimorphism

175 in Diictodon (most notably presence/absence of tusks, but associated with a suite of other cranial 
176 characters). Additionally, a nearly complete ontogenetic series is known for this taxon, ranging

177 from probable hatchlings (e.g., SAM-PK-K773 and SAM-PK-K10144) with total skull lengths

178 measuring less than two centimeters to large adults (e.g., SAM-PK-K6704) with skulls nearly 15

179 centimeters in total length. Finally, Diictodon has been the subject of intense taxonomic scrutiny

180 over the past two decades. Several studies based on qualitative comparisons as well as traditional

181 and geometric morphometric analyses have concluded that Diictodon represents a single

182 morphospecies, D. feliceps (King, 1993; Sullivan \& Reisz, 2005; Angielczyk \& Sullivan, 2008).

183 While additional research exploring the possibility of anagenesis in the lengthy Diictodon record

184 is warranted, taxonomic distinction is unlikely to represent a dominant source of morphological

185 variation in the sample.

186

187 Empirical data collection and analyses

188522 crania of Diictodon feliceps (composed of 518 specimens from South Africa, three

189 specimens from Zambia, and one specimen from China) were examined for this study. Of these

190 specimens, 485 were complete enough to have landmarks digitized on at least one side of the

191 skull in dorsal view, with 387 of those complete enough for a bilaterally-symmetric

192 configuration of dorsal landmarks, and 464 specimens were complete enough to have landmarks

193 digitized in lateral view (see associated dataset; Kammerer et al., 2020,

194 https://doi.org/10.5061/dryad.5tb2rbp1x). Specimen images were digitized using ImageJ and

195 TPSDig (Abràmoff, Magalhães \& Ram, 2004; Rohlf, 2010).

196 In dorsal view, we digitized a configuration of 16 landmarks consisting of four

197 midline landmarks and six pairs of bilaterally-symmetric lateral landmarks (Fig. 1A): (1) anterior

198 edge of premaxilla; (2 \& 11) Prefrontal-lacrimal sutural border at orbital margin; (3 \& 12) 
199 Anteroventral edge of postorbital bar; (4 \& 13) Posteroventral edge of postorbital bar; (5 \& 14)

200 Posterior extent of squamosal; (6 \& 15) Anteromedial edge of temporal fenestra; (7 \& 16)

201 Prefrontal-frontal sutural border at orbital margin; (8) Mid-frontal sutural border with

202 preparietal; (9) Anterior edge of pineal foramen; (10) Mid-parietal sutural border with 203 postparietal.

204 We analyzed two permutations of the dorsal view dataset. In the first dataset

205 ('dorsal'), we reflected bilaterally symmetric landmarks across the midline and averaged the 206 positions of the resulting pairs of landmarks to create a series of 'half specimens.' In cases where 207 a symmetric landmark was not preserved on one side of the skull, the coordinates of the single 208 preserved landmark were used. This approach follows common practice for dealing with 209 incomplete specimens in paleontological datasets, but the reflecting and averaging process can 210 affect both the biological and taphonomic signals in a dataset including distorted specimens (e.g.,

211 elimination of natural asymmetry, or creation of misleading mean values when one side of the

212 skull is highly sheared relative to the other) (Angielczyk \& Sheets, 2007). Therefore, we also 213 utilized a second dataset ('dorsal complete') consisting of only those specimens in which all

214 sixteen landmarks could be digitized. The resulting bilaterally symmetric landmark

215 configurations were then utilized in subsequent statistical analyses without reflecting and 216 averaging symmetric landmarks. For the lateral view, we digitized 11 landmarks (Fig. 1B): (1) Anteroventral tip of

218 premaxilla; (2) Anterior edge of canine/caniniform process; (3) Septomaxillary-nasal sutural

219 border at narial margin; (4) Posterior edge of canine/caniniform process; (5) Prefrontal-lacrimal

220 sutural border at orbital margin; (6) Prefrontal-frontal sutural border at orbital margin; (7)

221 Ventral edge of maxillary-jugal suture; (8) Postorbital-postfrontal sutural border at orbital 
222 margin; (9) Anteromedial edge of temporal fenestra; (10) Posterior extent of squamosal; (11)

223 Posterior edge of parietal. Images of specimens photographed in left lateral view were reflected

224 prior to digitization. If a specimen could be digitized for all lateral landmarks in left and right

225 views, the mean landmark coordinates of the two images were used for subsequent analysis.

226 Otherwise, only the single complete side was utilized.

Specimens were grouped by four variables: sex, size class, assemblage zone (AZ), and deformation style (see associated dataset; Kammerer et al., 2020). Sex was determined by the presence or absence of maxillary tusks, following Sullivan et al. (2003) in considering tusked individuals to be male and tuskless individuals to be female (although accurate identification of whether the tusked cohort represents males or females is not important for the purposes of our analyses, only the existence of a dimorphic pattern in the sample). In the smallest observed tusked specimen of Diictodon (BP/1/102, total skull length $4.87 \mathrm{~cm}$ ), the tusks are just erupting - all known smaller skulls are tuskless. Because the sex of these presumed juveniles cannot be determined, they were excluded from analyses using this variable. The specimens excluded from analyses of sex make up the 'small' size class, consisting of all specimens with a total skull length less than $5 \mathrm{~cm}$. The 'medium' size class consisted of specimens with total skull length ranging between 5 and $9 \mathrm{~cm}$, and the 'large' size class consisted of specimens with total skull length in excess of $9 \mathrm{~cm}$. Assemblage zone data were available for 419 specimens used in the dorsal analysis, 337 specimens used in the dorsal complete analysis and 391 used in the

241 lateral analysis. Assemblage zone data were derived from specimen labels, Haughton \& Brink 242 (1954), Kitching (1977), Smith (1993), and Rubidge (1995). Specimens were considered of

243 'unknown' assemblage zone and excluded from zonal analyses if they lacked locality data 244 altogether, had only vague locality information (e.g., "Cape Province"), or were collected 
245 without stratigraphic context at a locality known to span multiple assemblage zones. The largest

246 subset of specimens is from the Tropidostoma AZ, with 216 dorsal, 178 dorsal complete, and

247208 lateral landmarked specimens. The second largest sample is from the Cistecephalus AZ,

248 with 112 dorsal, 89 dorsal complete, and 102 lateral. From the Tapinocephalus AZ there are 47

249 dorsal, 37 dorsal complete, and 40 lateral. From the Daptocephalus AZ there are 24 dorsal, 16

250 dorsal complete, and 22 lateral. Lastly, from the Pristerognathus AZ there are 20 dorsal, 17

251 dorsal complete, and 19 lateral specimens. Deformation style was determined qualitatively $a$

252 priori (see "Patterns of Deformation" below). Many Diictodon skulls are subject to multiple

253 forms of distortion, in which case the dominant style of deformation was given precedence for

254 binning. Undeformed specimens were recognized based on consistent cranial symmetry,

255 uniformity of outline in easily distorted structures like the orbits and foramen magnum, and

256 sutural integrity (i.e., individual cranial bones not pulled apart or subducted beneath others).

257 Procrustes superimposition and principal components analysis (PCA) of landmark data

258 were performed using the program MorphoJ (Klingenberg, 2008). Meaningful PCA axes were

259 determined using the broken-stick method described by Jackson (1993), which distinguishes

260 between eigenvalues providing significant data structure and those that do not. The digitized

261 specimens of Diictodon listed above were also included in a broad-scale PCA covering all of

262 Anomodontia, with the sample composed of 1876 specimens in dorsal view and 1921 specimens

263 in lateral view (including Diictodon). Landmark protocol for this analysis was identical to that

264 for the within-group Diictodon study, with 'dorsal complete' landmarking used for skulls in

265 dorsal view. Anomodont specimens were binned into the higher-level taxa described by

266 Kammerer \& Angielczyk (2009) for calculation of within-group means when measuring

267 disparity. Procrustes variance-based morphological disparity was calculated for the anomodont- 
268 wide datasets using the 'morphol.disparity' function of the R (R Core Team, 2018) package

269 geomorph (Adams \& Otárola-Castillo, 2013). The significance of pair-wise differences in

270 disparity among groups was assessed via resampling over 500 iterations.

271

Procrustes ANOVAs were carried out in geomorph (Adams \& Otárola-Castillo, 2013)

272 to assess whether significant amounts of shape variation in our datasets can be ascribed to the

273 four study variables (sex, size class, AZ, and deformation style). The analyses using deformation

274 style as a factor were carried out on the full lateral, dorsal, and dorsal complete Diictodon

275 datasets. In contrast, the analyses focusing on biologically relevant variables (sex, size class, AZ)

276 were carried out using only the specimens in the 'undeformed' class from each dataset. When a

277 variable was determined to be significant, pairwise post-hoc tests were carried out to determine

278 whether significant differences in mean shape existed among the classes. Significance was

279 judged at a Bonferroni-corrected alpha level that was appropriate for the number of comparisons. 280

281 Simulations

282 A series of simulations was conducted using the program DefCat (part of IMP; Sheets, 2014),

283 with similar parameters to the simulation studies of Angielczyk \& Sheets (2007). DefCat

284 produces simulated deformed and non-deformed datasets in which both deformation and

285 underlying biological signals are known. Our basic protocol consisted of: 1) using non-deformed 286 empirical specimens near the ends of a biological continuum of variation to generate a series of

287 simulated non-deformed specimens that fall along that continuum; 2) creating deformed datasets

288 by using mathematical transformations to apply known types and amounts of deformation to the

289 datasets of simulated non-deformed specimens; and 3) assessing the amount of variance added to 
290 the datasets by deformation and testing whether accurate biological signals could be recovered

291 from the deformed datasets.

292

There were two simulated datasets with known biological signals that were subjected

293 to deformation. The first included a known ontogenetic signal, and the second included a sexual

294 dimorphism signal.

295

To make the simulated dataset with an ontogenetic signal, two undistorted Diictodon specimens of different sizes were chosen, one a representative 'small' individual and one a representative 'large' specimen. SAM-PK-K7838 served as the 'small' specimen for all of the 298 simulations because it is especially minute (skull length approximately $2.6 \mathrm{~cm}$, near the lower end of known specimens) and because landmarks could be digitized on it in each view. For the

300 dorsal complete dataset, the 'large' specimen was SAM-PK-K6041 (skull length approximately

$30110.1 \mathrm{~cm}$ ). The 'large' specimen in both the dorsal and lateral datasets was USNM 25157 (skull

302 length approximately $11.6 \mathrm{~cm}$; no complete, undistorted specimens near the maximum size for

303 Diictodon, $\sim 15 \mathrm{~cm}$, are known). DefCat was then used to generate as many simulated specimens

304 as we had empirical specimens. This meant 485 dorsal and 464 lateral simulated specimens

305 generated within each simulation. This evenly divides the size and shape differences between the

306 endpoint specimens, creating a simulated ontogenetic series of undeformed specimens. A small

307 amount of identical independent Gaussian noise was added to the data to simulate individual

308 variation among the specimens.

The second series of simulated datasets was created to test the effects of deformation

310 on sexual dimorphism. Here, two datasets were created using sets of either likely male or likely

311 female specimens, so that each dataset would be representative of either male or female

312 Diictodon. Following Sullivan et al.'s (2003) hypothesis that tusked individuals of Diictodon are 
313 likely male and tuskless individuals are likely female, two undeformed specimens of either sex

314 were used to create a series of simulated specimens that represent only one sex or the other. For

315 the dorsal complete datasets, BP/1/293 and SAM-PK-K1650 were chosen to represent males, and

316 BSPG 1934-VIII-48 and UCMP 42837 were chosen to represent females. For the dorsal view

317 datasets, NHMUK PV OR 47052 (the holotype of Diictodon feliceps) and SAM-PK-K1650 were

318 chosen to represent males, and BSPG 1934-VIII-48 and TM 299 were chosen to represent

319 females. For the lateral view datasets, NHMUK PV OR 47052 and TM 373 were chosen to

320 represent males, and BSPG 1934-VIII-48 and SAM-PK-K11484 were chosen to represent

321 females. In each case, the amount of simulated specimens reflect those in each category for the

322 empirical dataset, resulting in 251 simulated females and 220 males for the dorsal analysis, 194

323 females and 179 males for the dorsal complete analysis, and 238 females and 214 males for the

324 lateral analysis.

For each analysis, 100 simulated specimens were generated that evenly divide shape

variation among the starting specimens, with identical independent Gaussian noise added to the data to simulate individual variation.

To generate our deformed datasets, we used the deformation model described in configurations. Although shear deformation is only one of several types of deformation observed in specimens of Diictodon (see below), it provides an intuitive starting point for investigating the

332 potential effects of deformation on morphometric data for the species. The deformation model

333 has two main parameters, $\theta$ and $a$. The $\theta$ parameter alters the ratio of the long axis to the short

334 axis of the strain ellipse, whereas the $a$ parameter varies the strain ellipse ratio and the

335 orientation of the strain ellipse (details in Angielczyk \& Sheets [2007]). In addition to these 
336 parameters, the orientation of a specimen's landmark configuration relative to the strain ellipse

337 will alter the details of its resulting deformation. For example, if the long and short axes of the

338 specimen are aligned with the direction of applied stress, no shearing of the specimen will be

339 apparent, whereas shear will occur when the axes are not aligned. Therefore, an additional

340 parameter of the simulations is the range of angles specimens can take relative to the applied

341 stress, which can be random (i.e., ranging from $-180^{\circ}$ to $180^{\circ}$ ) or constrained to a smaller range

342 of angles to produce more stereotyped patterns of deformation in a given dataset.

A total of 18 groups of deformed datasets were generated, nine containing a simulated

344 ontogenetic signal and nine with a simulated sexual dimorphism signal. For a given biological

345 signal, each of the nine groups consisted of 16 individual datasets in which $\theta=1.0,1.5,2.0,2.5$,

$3463.0,3.5,4.0,4.5,5.0,6.0,7.0,8.0,9.0,10.0,15.0$, and 20.0 , with additional parameters varying

347 from group to group (Table 1). Each of the individual datasets contains 100 specimens. In Group

$3481, a=1.0$, all specimens were deformed, and the specimens were oriented randomly relative to

349 the direction of applied stress. Groups 2 and 3 had the same parameters as Group 1, except that

350 variable numbers of specimens were left undeformed (50\% deformed in Group 2, 94\% deformed

351 in Group 3). Groups 4 and 5 had the same parameters as Group 1 except that the orientation of

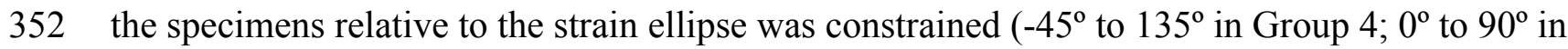

353 Group 5). Groups 6 and 7 had the same parameters as Group 1, but deformation amplitude (a)

354 was allowed to vary ( 0.95 to 1.0 in Group $6 ; 1.0$ to 1.05 in Group 7). All parameters were

355 allowed to vary in Groups 8 and 9 (Table 1).

356 We calculated Procrustes variance-based morphological disparity for all of the

357 simulated deformed datasets using the 'morphol.disparity' function of the R package geomorph

358 (Adams \& Otárola-Castillo, 2019). These values were then compared to disparity values for the 
359 corresponding empirical dataset (e.g., simulated deformed lateral view vs. empirical lateral view)

360 to determine which combinations of deformation parameters produced datasets with levels of

361 disparity comparable to our empirical sample. The significance of differences in disparity was

362 assessed using re-sampling. To determine whether an accurate ontogenetic signal was present in

363 our deformed datasets, we compared the size-correlated shape variation in each deformed dataset

364 to its corresponding undeformed dataset using a homogeneity of slopes test and an ontogenetic

365 trajectory analysis (Adams \& Collyer, 2009). An accurate ontogenetic trajectory was considered

366 recoverable if the slope and trajectory parameters for the deformed dataset did not differ

367 significantly from the parameters of the corresponding undeformed dataset. Analyses were also

368 carried out the geomorph package in R (Adams \& Otárola-Castillo, 2013).

369 To test the effects of deformation on the sexual dimorphism signal, we conducted

370 Procrustes ANOVAs in MorphoJ (Klingenberg, 2008) to determine whether simulated male

371 specimens differed significantly in mean shape from simulated females for each set of

372 deformation parameters. Of particular interest in the tests of ontogenetic and sexual dimorphism

373 signals was whether an accurate biological signal could be recovered from the simulated

374 deformed datasets with disparity levels closest to the observed value for the corresponding

375 empirical dataset.

376

377 RESULTS

378

379 Patterns of deformation

380 Although the amount of distortion in Diictodon crania exists along a continuum, deformation of

381 Diictodon fossils is not random. The structural properties of the cranium and the limited 
382 directionality of compaction of the surrounding sediment limit the range of deformation possible,

383 and nearly all Diictodon skulls can be assigned to one of seven typical styles of deformation

384 (Table 2). Most Diictodon crania are distorted to some degree-undistorted skulls account for

385 only $6 \%$ of specimens examined. Two general forms of deformational artifact that can influence

386 morphometric analysis were found in the study sample: artifacts of position and artifacts of

387 perspective. Artifacts of position represent the actual movement of one landmark relative to

388 others as a result of deformation. Artifacts of perspective represent apparent differences in shape

389 between two-dimensional images (e.g., photographs) of a distorted and undistorted specimen in

390 the same orientation. These differences are caused by deformation-induced changes in angulation

391 of various structures in the distorted specimen, resulting in landmarks that appear more distant or

392 closer together in the digitized image than they are in the actual specimen. Each major style of

393 deformation incurs both kinds of artifacts, the details of which are described below.

The typical styles of deformation in the Diictodon skull are illustrated in Figures 2-6,

395 and the prevalence of these deformational types is listed in Table 2. The simplest forms of

396 deformation, lateral (Fig. 2C,D) and dorsoventral (Fig. 2E,F) compression, are the most

397 commonly observed, with each making up roughly a third of the sample. These styles can be

398 related to unidirectional stress, probably the result of compaction of the overlying sediment on

399 skulls buried along their primary planes of rest (i.e., long axis parallel to the substrate, with the

400 skull lying on its lateral, dorsal, or ventral surface). Lateral compression is most strongly evident

401 in dorsal view, and is associated with decreased transverse dimensions of the skull and decreased

402 visible area of the orbits and temporal fenestrae. In lateral view, lateral compression is associated

403 with increased dorsoventral skull height, greater verticality of the postorbital bar (straighter, not

404 as curved as in undistorted skulls), increased visibility of the subtemporal fenestra, and a more 
405 perpendicular orientation of the quadrate ramus of the squamosal relative to the long axis of the

406 skull. Conversely, dorsoventral compression is most evident in lateral view, associated with

407 decreased dorsoventral skull height, decreased visibility of the subtemporal fenestra, and

408 posterior angulation of the quadrate ramus of the squamosal. In dorsal view, dorsoventral

409 compression is associated with increased transverse dimensions, increased visible area of the

410 orbits and temporal fenestrae, and greater horizontality of the postorbital (both for the postorbital

411 bar and its contribution to the intertemporal bar). The tusk and caniniform process are the most

412 robust and resistant portions of the Diictodon skull and generally display little change in

413 compressed skulls, but extreme dorsoventral compression can cause these structures to bend 414 anteriorly.

415 More unusual styles of deformation are shown in Figures 3-6. Of these, the most

416 common ( $\sim 11 \%$ of the sample) is the 'saddle-shape' (Fig. 3$)$, in which there is a marked

417 concavity in the dorsal profile of the skull in lateral view. This style of deformation is associated

418 with a seemingly shortened temporal region and elongated snout in dorsal view. However, these

419 apparent differences represent artifacts of perspective in the standard orientation, as the

420 intertemporal bar is angled downwards (making it appear shorter) and the snout is angled

421 upwards (making it appear longer, because the anterior edge of the premaxilla, normally directed

422 downwards and thus not visible in dorsal view, is exposed dorsally). The 'saddle-shape' can best

423 be interpreted as a variant style of dorsoventral compression related to the inherent architectural

424 properties of the dicynodont cranium. Although the dicynodont snout and posterior braincase are

425 robust, rigid structures (especially with the massive canine roots associated with the former in

426 most species), the midsection of the skull features relatively weak supporting elements (the

427 postorbital bars and the comparatively delicate midline ossifications of the braincase) between 
428 two major areas of soft tissue (the temporal musculature and eyes). Thus, in the presence of

429 compressive stress in the dorsoventral plane, it is expected that the midsection of the skull would

430 yield before the anterior or posterior regions, creating the 'saddle-shape'. Supporting this

431 interpretation, 'saddle-shaped' skull distortion is also observed (Fig. 3C,D) in all theriodont

432 therapsid groups (in which the snout/canine region is also generally more robust than the

433 orbitotemporal region), but not tapinocephalid dinocephalians, which possess massively

434 pachyostosed postorbital bars, relatively small temporal fenestrae and orbits, and internal skull

435 construction optimized for resisting forces applied to the dorsal surface of the skull (see, e.g.,

436 Barghusen, 1975; Benoit et al., 2017).

USNM 22948 (Fig. 4) represents a rare ( $\sim 5 \%$ of the sample) case of anteroposterior

438

439

440

441

442

443

444

445

446

447

compression. In this specimen, failure under compression occurred around the pineal foramen, such that the parietals were subducted under the frontals. Some cases of anteroposterior compression (e.g., BP/1/292) also exhibit the 'saddle-shape', probably as a result of the skull bending in on itself under stress. The rarity of anteroposteriorly compressed specimens in the sample can probably be attributed to the unusual circumstances required for its occurrence, necessitating either burial of a skull not on its primary plane of rest (i.e., long-axis perpendicular to the substrate) or tectonic influences (e.g., folding).

In addition to compression, various forms of deformation attributable to shear are observed in the study sample. Most distorted dicynodont specimens exhibit some degree of asymmetry as a result of shear (note the relative positions of the orbits and squamosals in Figure 2C and postorbital bars in Figure 4A), although complexly deformed skulls exhibiting marked distortion along multiple shear axes are rare. Of the varieties of shear-related cranial deformation, the most problematic for morphometric purposes is anterodorsal or 'face forward' 
451 shear ( $\sim 3.5 \%$ of the sample), as illustrated by BP/1/2317 (Fig. 5A,B). In this specimen, the

452 dorsal surface of the skull has been sheared forward, resulting in an artifact of perspective

453 (shortened snout) in dorsal view and actual positional changes (circumorbital landmarks shifted

454 anterior to the maxillary landmarks) in lateral view. Anteroventral ( $2 \%$ of the sample; Fig.

$4555 \mathrm{C}, \mathrm{D})$ and right/left ( $\sim 6 \%$ of the sample; Fig. 6$)$ sheared skulls are also observed in the sample.

456 In terms of the effects of deformation on the cranial landmarks used in this analysis,

457 each major style involves characteristic alterations of different suites of landmarks (although

458 degree of change varies with each specimen). For lateral compression, the primary positional

459 artifacts in dorsal view are medial movement of the set of landmarks along the lateral skull

460 surface $(2 / 11,3 / 12,4 / 13$, and $5 / 14)$, bringing them physically closer to the midline landmarks 8 ,

4619 , and 10. Greater proximity of landmarks along the ventral margins of the orbit and temporal

462 fenestra $(2 / 11,3 / 12$, and $4 / 13)$ to those on the dorsal margins $(6 / 15,7 / 16)$ is also observed, but

463 this can be attributed largely to perspective artifacts related to verticalization of the postorbital

464 bar and orbit. For example, in lateral view, landmarks 4/13 and 6/15 of a laterally compressed

465 skull are separated by either the same distance as in undistorted skulls or a slightly greater

466 distance (related to general increase in skull height), but in dorsal view the straightening of the

467 postorbital bar puts these landmarks in nearly the same plane (as the natural lateral curvature of

468 the postorbital bar is lost), sharply decreasing the distance between them in the projected image.

For dorsoventral compression, most of the changes in landmark position are the

opposite of those for lateral compression (e.g., in dorsal view, the skull edge landmarks move

471 laterally relative to the midline with increasing transverse dimensions of the skull), but with

472 some peculiarities. In lateral view, greater proximity between the set of landmarks along the base

473 of the skull $(1,7$, and 10) and those higher up $(3,5,6,8,9$, and 11) in projected images 
474 represents a combination of artifacts of perspective (e.g., greater horizontality of the postorbital

475 bar making landmark 7 appear closer to 8 and 9) and position (the more dorsal series of

476 landmarks has physically moved ventrally as a result of compression). Anterodorsal

477 displacement of landmarks 2 and 4 is also sometimes observed, in the extreme cases where the 478 tusk or caniniform process has bent anteriorly.

As noted above, 'saddle-shape' deformation results in decreased intertemporal length and increased snout length in dorsal view (artifacts of perspective), bringing the midline

481

482 483 landmarks either closer together (9 relative to 10$)$ or further apart ( 8 relative to 1$)$ than in an undistorted skull. In lateral view, the most affected landmarks are those around the dorsal margin of the orbit $(6,8$, and 9), which become displaced ventrally as a result of the collapse of the skull roof and postorbital bar. For anteroposterior compression, the primary change in both dorsal and lateral views is reduction in distance between all landmarks along the long axis of the skull. In lateral view, the skull also appears taller than in undistorted specimens (similar to the condition in laterally compressed specimens), resulting in greater separation between ventral $(1,2,4,7$, and 10) and dorsal $(3,5,6,8,9$, and 11) landmarks.

Anterodorsal shear results in a shorter observed snout in dorsal view (bringing landmark 8 closer to 1, the opposite of the 'saddle-shape' condition), but no change in observed length of the intertemporal bar (as the entire structure is displaced forwards, so the relative positions of landmarks along its length remain unchanged). In lateral view, dorsal landmarks (3, $5,6,8,9$, and 11) are generally displaced anteriorly relative to the ventral $(1,2,4,7$, and 10$)$ ones. The opposite is the case for anteroventral shear. Left/right shear results in variable landmark movement in lateral view, depending on which side of the skull is being digitized. 
496 Dorsally, it results in displacement of the pairs of symmetric landmarks on opposing sides of the

497 skull relative to one another, a result only captured in the dorsal complete analysis.

498

499 Principal components analysis of Diictodon feliceps crania: Lateral

500 Although they account for just $49.8 \%$ of the cumulative variance in the data set, only the first

501 two lateral PC axes contain meaningful structure under the broken-stick criterion. PC1 accounts

502 for $26.6 \%$ of variance in the lateral dataset. This PC describes relative skull height, snout depth,

503 and angulation of the temporal region (Fig. 7). Specimens with positive scores on PC1 exhibit

504 tall skulls relative to length, deep snouts, and short temporal regions with less oblique angles

505 between the temporal landmarks ( 9 and 11). PC2 accounts for $23.2 \%$ of variance in lateral data.

506 This PC primarily describes angulation of the face and temporal fenestra. In specimens with

507 positive scores on PC2, the face is angled forwards, such that circumorbital landmarks $(5,6,8)$

508 are more anterior and maxillary landmarks $(2,4)$ are more posterior than in the mean

509 configuration.

510 Deformation style is the only variable that shows clear structure in the PC1 vs. PC2

511 morphospace (Fig. 8B). Undistorted skulls cluster around the origin. Laterally and

512 anteroposteriorly compressed specimens generally have high positive scores on PC1, whereas

513 dorsoventrally compressed and 'saddle-shaped' specimens generally have high negative scores

514 on this PC, although there is significant overlap between these clusters at the origin.

515 Anteroventrally and right/left sheared specimens also tend to occupy the positive region of PC1,

516 although there are several marked outliers for the latter. The majority of anterodorsally sheared

517 specimens occupy a central position on PC1, with a few outliers. Direction of shear is the

518 dominant source of structure for PC2. Anteroventrally sheared specimens range from a central 
519 position to highly negative and all anterodorsally sheared specimens are positive on PC2.

520 Representatives of the other major styles of deformation vary widely on PC2, although the

521 majority of 'saddle-shaped' specimens occupy the negative region, a result attributable to the

522 anterodorsal angulation of the caniniform process relative to the orbits when a skull is bent at the

523 midsection. The other variables (size class, sex, and assemblage zone) exhibit random

524 occupation of PC1 vs. PC2 morphospace (Fig. 8).

525

526 Principal components analysis of Diictodon feliceps crania: Dorsal

527 Only the first two PC axes derived from the dorsal data set contain significant structure under the

528 broken-stick criterion, and together they account for $58.3 \%$ of cumulative variance in the data.

529 PC1 accounts for $38.4 \%$ of variance in the dorsal data. This PC describes snout length and

530 position of the postorbital bar (Fig. 9). Specimens with positive scores on PC1 exhibit relatively

531 short snouts and an anterior position for the dorsal limit of the postorbital bar (Landmark 6)

532 relative to the mean configuration. PC2 accounts for $19.9 \%$ of variance in the dorsal data. This

533 PC primarily describes skull breadth. Specimens with positive scores on PC2 exhibit transversely

534 narrow skulls in which the posterior tip of the intertemporal bar (Landmark 10) is situated

535 posterolateral to the mean configuration.

As with the lateral data, the only variable showing clear structure in PC1 vs. PC2

morphospace is deformation style (Fig. 10B). Direction of shear is associated with PC1, with

anterodorsally sheared specimens occupying positive PC1 space and anteroventrally sheared

539 specimens occupying neutral to negative PC2 space (with one outlier). Most other styles of

540 deformation show no pattern of association with PC1, although the majority of anteroposteriorly

541 compressed specimens also have a positive score on this PC. Direction of compression is 
542 associated with PC2. Laterally compressed specimens are generally positive on PC2, whereas

543 dorsoventrally compressed specimens are mostly negative. Anterodorsally sheared specimens

544 also show a notable cluster in negative space on PC2. The other variables (size class, sex, and

545 assemblage zone) exhibit random occupation of PC1 vs. PC2 morphospace (Fig. 10).

546

547 Principal components analysis of Diictodon feliceps crania: Dorsal Complete

548 Only the first two PC axes derived from the dorsal complete data set contain significant structure

549 under the broken-stick criterion, and together account for $47.0 \%$ of the variance in the data. PC1

550 accounts for $29.1 \%$ of the variance in the dorsal complete data. PC1 and PC2 both describe

551 information about length and breadth of the skull, though in different ways. PC1 describes

552 differences in anteroposterior length, showing changes associated with shortening of the back of

553 the skull for specimens with high positive scores (Fig. 11A). It also shows changes in the

554 transverse breadth of the skull, with transversely wider specimens scoring higher on this axis.

$555 \mathrm{PC} 2$, on the other hand, captures information about length change near the front of the skull.

556 Specimens with high positive scores in PC2 have relatively shortened snouts compared to the

557 mean configuration (Fig. 11B). Specimens scoring high on PC2 are also transversely wider than

558 the mean shape of the dataset in the temporal region, but narrower in the snout.

Like the lateral and dorsal data, the predominant variable showing clear structure in

PC1 vs. PC2 morphospace for dorsal complete is deformation style (Fig. 12B). Laterally

561 compressed specimens tend to have low to moderate scores on PCs 1 and 2, whereas

562 dorsoventrally compressed specimens tend to have higher scores on both PC axes.

563 Anteroposteriorly deformed specimens generally have high positive scores on PC1 and

564 anterodorsally sheared specimens generally have high positive scores on PC2. Assemblage zone 
565 data, skull size and sex show largely random distribution in the morphospace (Fig. 12).

566 Specimens from the Daptocephalus AZ do tend to mostly have higher values on PC1 and lower

567 values on PC2, but they are broadly overlapped by specimens from the other assemblage zones

568 on these axes.

569

570 Procrustes ANOVAs

571 Deformation style was found to explain a significant amount of variation in all three empirical

572 datasets, but significant results were rarer for the biologically relevant factors (see associated

573 dataset; Kammerer et al., 2020, https://doi.org/10.5061/dryad.5tb2rbp1x). Only size class was

574 found to be significant in the dorsal $(\mathrm{p}=0.021)$ and dorsal complete $(\mathrm{p}=0.048)$ datasets

575 (undeformed specimens only), although sex and AZ approached significance in some cases (p-

576 values range between 0.071 and 0.622 ). The pairwise comparisons revealed that the different

577 deformation styles usually have significantly different mean shapes (20 out of 21 comparisons

578 significant for the dorsal, dorsal complete, and lateral data), and also differ significantly from the

579 undeformed specimens in the majority of cases (4 out of 7 comparisons significant for the dorsal

580 and dorsal complete data, 5 out of 7 for the lateral), even under the rather stringent Bonferroni-

581 corrected alpha level of 0.002 . The cases where the mean shapes did not significantly differ are

582 generally logical when one considers the way in which the deformations styles tend to alter

583 specific aspects of shape. For example, laterally compressed and right/left sheared specimens do

584 not have mean shapes that differ significantly from undeformed specimens in the lateral view

585 datasets because these deformation types tend to have relatively mild effects on shape when

586 viewed from the side. Among the pairwise comparisons for the size classes, only medium and 
587 small specimens in the dorsal complete dataset had a significantly different shape at the

588 Bonferroni-corrected alpha of 0.02 .

589

590 Analysis of Diictodon within Anomodontia

591 For the all-anomodont lateral PCA including only undistorted Diictodon specimens, the first four

592 PC axes account for $70.6 \%$ of cumulative variance in the data. PC1 accounts for $29.2 \%$ of

593 variance and describes general skull height, snout depth, and temporal fenestra length (Fig. 13A).

594 Specimens with positive scores on PC1 have relatively low skulls, shallow snouts, and long

595 temporal fenestrae. The majority of anomodont diversity occupies positive PC1-space, with high

596 negative scores largely restricted to the extremely deep-snouted lystrosaurids (Fig. 14). PC2

597 accounts for $17.7 \%$ of variance in the data and describes relative snout length, orbital height, and

598 temporal/occipital angulation (Fig. 13B). Emydopoids (especially the fossorial cistecephalids)

599 generally have high positive scores on PC2 and are characterized by very short snouts, large

600 orbits, and a tall occiput with the posterior edge of the parietal located slightly anterodorsal to the

601 posterior edge of the squamosal. Kannemeyeriiforms, rhachiocephalids, and some basal

602 dicynodontoids generally have high negative scores on PC2 and are characterized by long snouts,

603 small orbits relative to skull size, and a very long temporal region where the posterior edge of the

604 parietal is located far anterior to the posterior edge of the squamosal. PC3 accounts for $13.6 \%$ of

605 variance in the data and describes angulation of the postorbital bar and height of the temporal

606 fenestra (Fig. 13C). Cistecephalid emydopoids have high negative scores on PC3 and are

607 characterized by an anterior position for the junction between the postorbital bar and zygoma and

608 tall temporal fenestra. Finally, PC4 accounts for $10.0 \%$ of variance in the data and describes

609 orbital width and maxillary/tooth row length (Fig. 13D). Non-dicynodont anomodonts 
610 ("dromasaurs" and venyukovioids) have high positive scores on PC4 and are characterized by

611 very wide orbits and long snouts with marginal dentition (as opposed to the single tusk and/or

612 few postcanines of most dicynodonts). Undistorted Diictodon specimens occupy a location near

613 the origin in all significant PC plots (Fig. 14).

The results of the all-anomodont lateral PCA including deformed Diictodon specimens

615 were similar to the previous analysis. The first four PCs account for a cumulative $70.1 \%$ of

616 variance in the data, with $\mathrm{PC} 1$ contributing $28.5 \%$, PC2 contributing $17.7 \%, \mathrm{PC} 3$ contributing

617 13.7\%, and PC4 contributing 10.3\%. The morphological differences described by these PCs are

618 the same as in the previous analysis, and morphospaces constructed using these PC axes are

619 generally similar to those illustrated above (Fig. 15). Deformed Diictodon specimens occupy a

620 much broader range of morphospace than in the previous analysis, however, and the Diictodon

621 cluster overlaps much of anomodont diversity on PCs 2 and 3, with a few outliers even

622 impinging on lystrosaurid negative space on PC1 (Fig. 16). Procrustes variance-based

623 morphological disparity for Anomodontia (calculated as was done for the simulated deformed

624 datasets, using the 'morphol.disparity' function of the R package geomorph [Adams \& Otárola-

625 Castillo, 2013]) does not appreciably differ between the data containing only undistorted

626 (0.0334) and all Diictodon specimens (0.0336), however.

For the all-anomodont dorsal complete PCA including only undistorted D. feliceps

628 specimens, the first four PC axes account for $71.1 \%$ of cumulative variance in the dataset. The

629 first three PC axes show strong phylogenetic signal based on qualitative observation of the

630 morphospace. PC 1 accounts for $39.0 \%$ of variance in the data and describes relative skull length

631 (Fig. 17). The extremely short-skulled cistecephalid emydopoids and lystrosaurids have high

632 positive scores on PC1 (Fig. 18). PC2 accounts for $14.7 \%$ of variance in the data and describes 
633 angulation of the orbits and temporal region. Cistecephalid emydopoids have high positive

634 scores on PC2 and are characterized by forward-facing orbits and squared-off temporal regions

635 in which the posterior edges of the squamosals occupy the same transverse axis of the skull as

636 the posterior edge of the parietal. PC3 accounts for $11.6 \%$ of variance in the data and describes

637 temporal fenestra length and breadth. Cryptodonts generally have high positive scores on PC3

638 and are characterized by very broad temporal fenestrae, whereas most emydopoids have negative

639 loadings on PC3 and relatively narrow fenestrae in dorsal view. Diictodon occupies low negative

640 space on $\mathrm{PC} 1$ and 2 and is broadly distributed on PC3. PC4 accounts for $5.6 \%$ of variance in the

641 data and describes the effects of right/left shear (Fig. 17). Positive scores on PC4 are associated

642 with a relatively posterior position for landmarks on the left side of the skull and anterior

643 position for those on the right; negative scores are the opposite. This result indicates that even

644 though phylogenetic signal accounts for the majority of variance in higher-level analyses of

645 Anomodontia, and even with the large sample of deformed Diictodon specimens excluded, there

646 is still a significant taphonomic signal in this data. An unusually high number of

647 kannemeyeriiforms occupy positive PC4 space, and a number of cryptodonts and basal

648 dicynodontoids also occupy this space (Fig. 18). These three groups represent the anomodonts

649 with the proportionally largest temporal fenestrae. Although all lateral skull margin landmarks

650 show movement from the mean on PC4, the greatest magnitude of change is along the landmarks

651 surrounding the temporal fenestra $(4 / 13,5 / 14)$. Given that the subtemporal bar bounding the

652 temporal fenestra is a relatively thin structure in these taxa, they are probably disproportionately

653 susceptible to high degrees of deformation in this region.

654 Including deformed Diictodon specimens in the all-anomodont dorsal complete

655 analysis yields similar primary sources of variation as in the prior analysis. The first four PCs 
656 account for a cumulative $70.1 \%$ of variance in the data, with PC1 contributing $37.9 \%$, PC2

657 contributing $15.3 \%$, PC3 contributing 10.3\%, and PC4 contributing $6.6 \%$. The addition of

658 deformed Diictodon specimens alters the shape of anomodont morphospace, but does not

659 appreciably change its structure (i.e. the same taxa occupy the same regions of morphospace;

660 Fig. 19). As for the lateral analysis, the deformed specimens occupy a much broader range of

661 morphospace than observed for this taxon when only undistorted specimens are included (Fig.

662 20). This is also reflected in the Procrustes variance for undistorted vs. all Diictodon specimens

663 (0.222 vs. 0.428 respectively). Procrustes variance for Anomodontia as a whole does not change

664 significantly whether only undistorted or all Diictodon specimens are included, however (0.2741

665 vs. 0.2702 respectively).

666

667 Simulations

668 We calculated the morphological disparity present in each of our simulated deformed datasets

669 and mapped it to observed disparity in the empirical datasets. For the first four sets of parameters

670 in the dorsal and lateral datasets, and the first five in the dorsal complete dataset, disparity in the

671 simulated datasets was lower than in the empirical datasets at low values of $\theta$ and higher at high

$672 \theta$ values. However, simulated disparity was close to empirical at values of $\theta$ in the 7.0 to 15.0

673 range, with the greatest similarities usually in the range of 8.0 to 10.0 . These simulated datasets

674 did not show significantly different disparity from the observed empirical datasets. For parameter

675 sets 6 through 9 simulated disparity was always higher than in the empirical datasets. We

676 consider the simulated datasets with disparities close to empirical levels to be the most relevant

677 for further tests of whether we can accurately recover biological signals from datasets including 
678 deformed specimens, with simulated datasets with higher or lower disparity levels representing

679 "worst case" and "best case" scenarios, respectively.

680 In the trajectory analysis, each simulated deformed dataset was compared to its

681 simulated non-deformed counterpart. Specifically, we considered three parameters of the

682 ontogenetic trajectories: 1) their lengths (trajectory size); 2) their orientations in relation to each

683 other (trajectory orientation; measured by principal vector correlation); and 3) the paths their

684 trajectories take through shape space (trajectory shape) (Adams \& Collyer, 2009).

685 For the majority of the datasets, there was no significant difference between the

686 ontogenetic trajectories of the deformed and non-deformed datasets. The aspect that showed the

687 largest difference between trajectories was trajectory size. In the lateral datasets, $6.7 \%$ of the

688 datasets showed significant differences in disparity between empirical and simulated datasets. In

689 the dorsal datasets, $9 \%$ showed significant differences, and in the dorsal complete datasets, $5.8 \%$

690 showed significant differences. Combined, $21.5 \%$ of the datasets showed significant differences

691 in trajectory size between the empirical and simulated datasets, and $78.5 \%$ showed no significant

692 difference. In the lateral datasets, differences were most often found between $\theta 1.0$ and 2.5 and

693 above $\theta 6.0$, but was less common between $\theta 2.5$ and 6.0. Differences were found for each

694 parameter group except for parameter group 2, and were most often seen in groups 6 through 9 .

695 In the dorsal and dorsal complete datasets, differences were found for each parameter group

696 except for group 5. Just as with lateral, differences were most often found in parameter groups 6

697 through 9.

698

The second most common difference was trajectory shape. In the lateral datasets, $4.6 \%$

699 of the data showed significant differences between the non-deformed and deformed trajectory

700 shapes. In dorsal, $3.5 \%$ showed significant differences, and in dorsal complete, $4.4 \%$ showed 
701 significant differences. In total, $12.5 \%$ of the data showed significant differences in trajectory

702 shape, with $87.5 \%$ showing insignificant differences. In the lateral datasets, differences were

703 found for parameter groups 3 and 5 through 9, but not 1, 2, or 4 . For dorsal, differences were

704 found in parameter groups 4 and 6 through 9, but not 1 through 3 or 5 . In dorsal complete,

705 differences were found in all parameter groups except group 2. As with trajectory size, trajectory

706 shape showed most prevalent difference in parameter groups 6 through 9.

707

Significant differences in trajectory orientation were very uncommon. There were only

708 three instances of significant differences in trajectory orientation in the lateral view datasets

709 (theta 1.0 in parameter sets 7 and 9, and theta 10.0 in parameter set 8), two instances in the

710 dorsal view datasets (theta 3.5 in parameter set 8 and theta 10.0 in parameter set 9), and none in

711 the dorsal complete datasets.

712

The analytical procedure for the homogeneity of slopes test was the same as for the

713 ontogenetic trajectory analysis, with the slope of the deformed dataset being compared to that of

714 its non-deformed counterpart. The results of the analysis were similar to those of the trajectory

715 analysis, with significant differences in slope rarely occurring between simulated deformed and

716 non-deformed datasets. In the lateral datasets, significant differences occurred only 3 times. In

717 dorsal, significant differences occurred 10 times, and in dorsal complete, significant differences

718 occurred 11 times. In total, significant differences were found in $5.5 \%$ of all of the datasets, and

719 there was no significant difference in slope for $94.5 \%$ of the datasets. There was no real trend for

720 the thetas at which these differences would occur, but it was more common in parameter groups

7215 through 9 in the dorsal and dorsal complete datasets.

722

Taken together, these results imply that it may be possible to recover an accurate

723 ontogenetic signal from therapsid datasets that include deformed specimens, even in cases where 
724 the amount of disparity contributed by deformation exceeds what is observed in the empirical

725 Diictodon dataset.

726

Our analysis of the effects of deformation on a sexual dimorphism signal focused on

727

728

729

730

731

732

733

\section{DISCUSSION}

735

736

737

738

739

740

741

742

743

744

745

746

whether we could recover a significant difference in shape between sets of simulated deformed male and female specimens. The results of our Procrustes ANOVAs comparing deformed male and female datasets were very straightforward: a significant difference between males and females was preserved in all of the deformed datasets, regardless of the starting deformation parameters. This finding indicates that it may be possible to identify instances of sexual dimorphism in therapsid morphometric datasets even when deformed specimens are included.

The results of the principal components analyses of Diictodon crania strongly indicate that deformation is the dominant source of morphological variance in the lateral, dorsal, and dorsal complete empirical datasets. The Procrustes ANOVA results corroborate these observations, with deformation always having a significant effect, and deformation styles having significantly different mean shapes in the majority of cases. Deformation style exhibits considerable structure in PC1 vs. PC2 morphospace, with almost all major styles of deformation occupying a characteristic region of morphospace. Left/right shear is the sole exception to this pattern, with specimens more evenly distributed in morphospace. This likely stems in part from averaging of symmetric landmarks during the construction of the lateral and dorsal datasets, which is expected to remove some effects of shear deformation (Angielczyk \& Sheets, 2007). However, the pattern is also apparent in the dorsal complete dataset, which does not have averaged landmark 
747 coordinates. We hypothesize that this is because specimens can be affected by shearing in

748 different ways (e.g., 'left side forward' versus 'right side forward'), resulting in skull shapes that

749 do not cluster together in morphospace. The structuring of specimens in morphospace according

750 to their deformation style is similar to that observed in an analysis of deformed skulls of the

751 dinosaur Psittacosaurus (Hedrick \& Dodson, 2013), suggesting that this pattern may be

752 ubiquitous in fossil skull datasets with relatively large sample sizes. Hedrick et al. (2019)

753 recently demonstrated substantial morphospace dispersion of deformed Psittacosaurus

754 postcrania as well, regardless of base morphology (i.e., flat vs. columnar) of the bones in

755 question. Although architectural properties of elements clearly have some influence on proclivity

756 to distortion and the effects thereof (see "Patterns of deformation" above and discussion by

757 Tschopp et al. (2013)), deformation appears to represent an important factor structuring

758 morphospace across elements in fossil specimens.

In contrast to the strong signal from deformation style, Diictodon specimens

760 categorized by the biological variables of sex and size class (a proxy for age) exhibit seemingly

761 random occupation of morphospace. Krone et al. (2019) were able to recover an ontogenetic

762 signal for Diictodon skulls in lateral view using a smaller sample of more or less undeformed

763 specimens and a slightly different configuration of landmarks in lateral view. The absence of an

764 obvious size-shape relationship in the empirical data here suggests that it was overprinted by

765 deformation, mirroring Hedrick \& Dodson's (2013) conclusion that their Psittacosaurus dataset

766 did not preserve an original allometric signal. It also appears that size class and sex have only a

767 weak effect on overall skull shape in Diictodon under even the best circumstances. These factors

768 typically explained only about $10-15 \%$ of the shape variance among the undeformed specimens

769 in our datasets. 

categorized by assemblage zone in the PC plots, and assemblage zone also explained about $20 \%$

772 of the shape variance among our undeformed specimens in the Procrustes ANOVAs. Most

773 Daptocephalus AZ specimens displayed lower scores on PC2 for the dorsal and dorsal complete

774 datasets, and mostly higher scores on PC1 for the dorsal complete dataset. These positions can be

775 accounted for by the absence of any anterodorsally sheared specimens in the Daptocephalus AZ

776 sample. We interpret the lack of anterodorsal deformation among Daptocephalus AZ specimens

777 to be an artifact of small sample size, because anterodorsal shear is one of the rarest styles of

778 deformation (albeit one with an outsized influence on morphospace), and the Daptocephalus AZ

779 is the second smallest sample. Moreover, several specimens of the Daptocephalus AZ index

780 taxon Daptocephalus leoniceps clearly exhibit anterodorsal shear (e.g., BP/1/555, NMQR 960),

781 allowing us to reject a change in basin-wide deformation style as the source of the pattern. The

782 morphometric heterogeneity of specimens from the different assemblage zones provides some

783 corroboration of the hypothesis that only a single species of Diictodon (D. feliceps) is present in

784 the Karoo Basin (Sullivan et al. 2003; Sullivan \& Reisz, 2005; Angielczyk \& Sullivan, 2008),

785 but this conclusion is tempered by the possibility that deformation might have overprinted an

786 underlying taxonomic signal in the data. Furthermore, the presence of low-level variance tied to

787 assemblage zone even among undeformed skulls suggests there could be merit in exploring 788 possible anagenetic variation in the Diictodon record.

790 specimens belonging to the higher-level clades used in binning tend to cluster together.

791 However, the relationships between these clades (as recovered in recent phylogenetic analyses,

792 e.g. Angielczyk \& Kammerer, 2017; Kammerer et al., 2019) are not clearly reflected by their 
793 relative positions in morphospace. Undistorted Diictodon specimens occupy positions near the

794 mean on PCs 1-3 in the lateral analyses, and deformed specimens are dispersed widely around

795 this region in all directions. In the dorsal analysis, undeformed specimens tend to have negative

796 scores on PCs 1-3, and again the addition of deformed specimens causes the occupied area to

797 expand uniformly in all directions from this starting point. In each case, essentially the same PC

798 axes are recovered regardless of deformation in Diictodon, indicating that for the analysis of total

799 occupied morphospace at broad taxonomic scales, inclusion of deformed specimens is not

800 misleading. Within anomodont morphospace, however, it is clear that the extent occupied by

801 Pylaecephalidae (and Diictodon feliceps specifically) has been greatly expanded by the deformed

802 specimens, with especially troubling implications for between-group measures of disparity at

803 lower taxonomic levels.

804 Given the strong apparent phylogenetic signal in anomodont morphospace, the

805 inclusion of deformed taxonomic singletons is warranted in clade-level analyses of

806 morphological disparity. Because undistorted specimens are so rare $(<6 \%$ of the sample in the

807 case of heavily-sampled Diictodon), the likelihood of anomodont singletons preserving the

808 undistorted cranial morphology of their species is low. Nevertheless, our morphospace results

809 indicate that even if a deformed specimen does not occur precisely where it would if it was not

810 deformed, the majority of deformed specimens still fall in the region occupied by their larger

811 clade. This result is encouraging for analyses that seek to maximize taxonomic inclusivity. It is

812 notable, however, that even at this broad scale, some variation due to taphonomic overprinting

813 can be discerned, with PC4 from the all-anomodont dorsal complete analysis being related to

814 specimen shear. 
816 datasets. However, in most or all cases we were able to recover an accurate (simulated)

817 ontogenetic or sexual dimorphism signal from the simulated datasets, whereas there was no

818 obvious structure associated with these factors in the empirical datasets that included deformed

819 specimens. A possible explanation for this difference in the empirical and simulation results is

820 the fact that the simulations utilized only a single kind of deformation (shear), in contrast to the

821 multiple types of deformation experienced by the empirical specimens. The latter case might

822 overprint the shapes of specimens to a greater degree than a more stereotyped deformation style,

823 even if the various deformation styles tend to segregate into specific regions of morphospace.

824 Therefore, although the simulation results raise the possibility that it might be possible to recover

825 accurate biological signals from datasets including deformed specimens, this likely will be

826 difficult in practice. One potential approach for trying to extract biological information from

827 deformed specimens would be to conduct the analyses on groups of specimens sharing a similar

828 deformation style, which might result in datasets more similar to our simulated data. Somewhat

829 counterintuitively, it seems this is a case where a more restricted sample is more likely to recover

830 biological signal. However, even a restricted sample could be misleading if the direction of

831 deformation overlaps with the biological signal. As an example, Jasinoski and Abdala (2017)

832 recognized sexual dimorphism in the Triassic cynodont Galesaurus, with one morph

833 characterized by a generally broader skull than the other (especially evident in the transverse

834 dimensions of the snout and zygomatic arches). This pattern was observed in a number of

835 undistorted skulls in association with other features, suggesting that it is not the result of a

836 taphonomic overprint. In a sample of only dorsoventrally or laterally compressed skulls, 
837 however, this pattern would not be discernible with confidence, given the strong influence of

838 these deformation styles on skull breadth.

Alternatively, given that deformation in both our simulated and empirical datasets

840 seems to add variance in a roughly even fashion in all directions in morphospace, it may be that

841 our simulated datasets have clearer biological signals than would be the case in the empirical

842 data even if deformation was absent. We used empirical specimens as the starting points for our

843 simulated datasets, but the specimens chosen were relatively extreme shapes (e.g., very large and

844 very small undistorted empirical specimens for the simulated datasets with an ontogenetic

845 signal), which could result in an exaggerated 'biological' signal. However, the simulated

846 ontogenetic signal in our lateral view dataset is quite similar to that documented by Krone et al.

847 (2019) for Diictodon (larger specimens have proportionally deeper snouts and are more

848 dorsoventrally constricted near the level of the orbits), so we do not think we have seriously

849 mischaracterized the biological signals included in the simulated datasets. Instead, we consider it

850 more likely that better preserved biological signals in the simulated deformed datasets is a

851 reflection of the simpler style of deformation applied in the simulations.

852 A final aspect of both our empirical and simulated datasets that warrants discussion is

853 their comparatively large sample size. Diictodon is the single most common dicynodont in the

854 Permian rocks of the Beaufort Group in the Karoo Basin (e.g., Smith et al. 2012), and the very

855 high percentage of deformed specimens in the empirical dataset underscores how ubiquitous

856 taphonomic deformation is in Karoo fossils. The large sample also facilitates a detailed

857 characterization of different deformation styles, and helps to show that biological signals such as

858 ontogeny and sexual dimorphism are not major sources of variation in the dataset compared to

859 the effects of deformation. However, most Karoo synapsid taxa are represented by fewer (often 
860 many fewer) specimens. Given that Diictodon shows several stereotyped styles of deformation

861 that differ considerably in shape, it is easy to see why the effects of deformation have been such

862 a confounding factor in Karoo synapsid taxonomy, particularly in cases where species are

863 represented by only a handful of specimens. Recent taxonomic work has been more circumspect

864 about the potential effects of deformation, and our finding that deformation can overprint

865 biological signals indicates that similar care is necessary in studies that seek to quantify

866 morphological variation. More optimistically, it is worth noting that the Diictodon specimens

867 studied here are quite old, ranging from Capitanian to Changhsingian in age (e.g., Day et al.,

868 2015; Gastaldo et al. 2015), providing ample time for them to experience deformation during the

869 Karoo Basin's complex tectonic history. We predict that the severity of deformation and its

870 effects on important biological signals will decrease on average with decreasing age of the fossils

871 under consideration, so our results should not be used to dismiss all geometric morphometric

872 studies of fossils out of hand. However, the existence of more recent examples such as the

873 famously deformed Oligocene-Miocene leptaucheniine oredonts of North America (e.g.

874 Prothero \& Sanchez, 2008) suggest a quantitative test of this hypothesis would be enlightening.

875

876 CONCLUSIONS

877

878 Distortion of Diictodon crania is not random, and can be classified into seven stereotyped

879 deformation styles influenced by planes of compression and underlying architectural properties

880 of the dicynodont skull. The cumulative effect of these deformation styles on morphospace,

881 however, is indeed random dispersion around an undistorted origin. Within Diictodon feliceps,

882 the only signal in morphological variance is associated with deformation style. Although 
883 simulated datasets indicate that it is possible to extract accurate biological signals from

884 geometric morphomeric datasets including deformed specimens, our empirical results suggest

885 that the more complex styles of deformation encountered when working with real specimens will

886 likely make such success difficult in practice (mirroring the practical difficulties involved in pre-

887 analytical retrodeformation of large samples). Therefore, we recommend caution in intraspecific

888 analyses of variation in non-mammalian synapsids, as differences interpreted as biological

889 variation may simply represent deformational artifact. This concern may be broadly applicable

890 for fossil taxa, as demonstrated by other empirical and theoretical analyses (e.g., Webster \&

891 Hughes, 1999; Angielczyk \& Sheets, 2007; Hedrick \& Dodson, 2013; Baert et al., 2014; Hedrick

892 et al., 2019). Less caution is required in the inclusion of deformed individuals in large,

893 multispecies data sets. Although the range of morphospace occupation will be larger than in

894 biological reality for deformed specimens, the random dispersion caused by deformation allows

895 one to confidently infer actual position in morphospace for the within-species mean. Deformed

896 singletons may occupy a misleading position in morphospace, but the relative import of

897 phylogenetic signal reduces interpretive error in this case. Although deformed specimens incur

898 minimal error of disparity metrics when within-group taxon means are used, a taxon-free

899 approach underestimates overall disparity within the group, highlighting the need for thorough

900 taxonomic review underlying analyses of disparity that include deformed specimens.

901

902 INSTITUTIONAL ABBREVIATIONS

903 BP Evolutionary Studies Institute, University of the Witwatersrand, Johannesburg, South

904 Africa

905 BSPG Bayerische Staatssammlung für Paläontologie und Geologie, Munich, Germany 
906 NHMUK The Natural History Museum, London, United Kingdom

907 NMQR National Museum, Bloemfontein, South Africa

908 SAM Iziko, the South African Museum, Cape Town, South Africa

909 TM Ditsong National Museum of Natural History, Pretoria, South Africa

910 UCMP University of California Museum of Paleontology, Berkeley, USA

911 USNM National Museum of Natural History, Washington, D.C., USA.

912

913 ACKNOWLEDGEMENTS

914

915 We thank the collections managers and curators of the many Diictodon-bearing institutions who 916 provided access to material for this study.

917

918 REFERENCES

919

920

921

Abràmoff MD, Magalhães PJ, Ram SJ. 2004. Image Processing with ImageJ. Biophotonics International 11(7):36-42.

Adams DC. 2014. Quantifying and comparing phylogenetic evolutionary rates for shape and

923 other high-dimensional phenotypic data. Systematic Biology 63(2):166-177.

Adams DC, Collyer ML. 2009. A general framework for the analysis of phenotypic trajectories 925 in evolutionary studies. Evolution 63(5):1143-1154.

926

Adams DC, Otárola-Castillo E. 2013. Geomorph: an R package for the collection and analysis 927 of geometric morphometric shape data. Methods in Ecology and Evolution 4:393-399. 
928 Angielczyk KD. 2007. New specimens of the Tanzanian dicynodont "Cryptocynodon"

929

930

931

932

933

934

935

936

937

938

939

940

941

942

943

944

945

946

947

948

parringtoni von Huene, 1942 (Therapsida, Anomodontia), with an expanded analysis of Permian dicynodont phylogeny. Journal of Vertebrate Paleontology 27(1):116131.

Angielczyk KD, Kammerer CF. 2017. The cranial morphology, phylogenetic position and biogeography of the upper Permian dicynodont Compsodon helmoedi van Hoepen (Therapsida, Anomodontia). Papers in Palaeontology 3:513-545.

Angielczyk KD, Kammerer CF. 2018. Non-mammalian synapsids: the deep roots of the mammalian family tree. Pp. 117-198 in Zachos, F. E. and Asher R. J. (eds.); Handbook of Zoology: Mammalia: Mammalian Evolution, Diversity and Systematics. De Gruyter, Berlin.

Angielczyk KD, Sheets HD. 2007. Investigation of simulated tectonic deformation in fossils using geometric morphometrics. Paleobiology 33(1):125-148.

Angielczyk KD, Sullivan C. 2008. Diictodon feliceps (Owen, 1876), a dicynodont (Therapsida, Anomodontia) species with a Pangaean distribution. Journal of Vertebrate Paleontology 28(3):788-802.

Angielczyk KD, Steyer J-S, Sidor CA, Smith RMH, Whatley RL, Tolan S. 2014. Permian and Triassic dicynodont (Therapsida: Anomodontia) faunas of the Luangwa Basin, Zambia: Taxonomic update and implications for dicynodont biogeography and biostratigraphy. In: Kammerer CF, Angielczyk KD, Fröbisch J., eds. Early Evolutionary History of the Synapsida. Dordrecht: Springer, 93-138, 337. 
949 Arbour VM, Currie PJ. 2012. Analyzing taphonomic deformation of ankylosaur skulls using 950 retrodeformation and finite element analysis. PLoS ONE 7(6):e39323.

951

952

953

954

955

956

957

958

959

960

961

962

963

964

965

966

967

968

969

970

971 regalis (Dinosauria: Hadrosauridae) postcranial elements from the Danek Bonebed, Upper Cretaceous Horseshoe Canyon Formation, Edmonton, Alberta, Canada: implications for allometric studies of fossil organisms. Canadian Journal of Earth Sciences 51(11):1007-1016.

Barbolini N, Bamford MK, Rubidge B. 2016. Radiometric dating demonstrates that Permian spore-pollen zones of Australia and South Africa are diachronous. Gondwana Research 37:241-251.

Barghusen HR. 1975. A review of fighting adaptations in dinocephalians (Reptilia, Therapsida). Paleobiology 1(3):295-311.

Benoit J, Manger PR, Norton L, Fernandez V, Rubidge BS. 2017. Synchotron scanning reveals the palaeoneurology of the head-butting Moschops capensis (Therapsida, Dinocephalia). PeerJ 5:e3496.

Berman DS, Reisz RR, Bolt JR, Scott D. 1995. The cranial anatomy and relationships of the synapsid Varanosaurus (Eupelycosauria: Ophiacodontidae) from the Early Permian of Texas and Oklahoma. Annals of Carnegie Museum 64:100-133.

Bookstein FL. 1991. Morphometric Tools for Landmark Data: Geometry and Biology. Cambridge: Cambridge University Press, 435 pp.

Botha J, Angielczyk KD. 2007. An integrative approach to distinguishing the Late Permian dicynodon species Oudenodon bainii and Tropidostoma microtrema (Therapsida: Anomodontia). Palaeontology 50(5):1175-1209. 
972 Brocklehurst N, Day M, Rubidge B, Fröbisch J. 2017. Olson's Extinction and the latitudinal

973

974

975

976

977

978

979

980

981

982

983

984

985

986

987

988

989

990

991

992

993

biodiversity gradient of tetrapods in the Permian. Proceedings of the Royal Society B 284:20170231. 10.1098/rspb.2017.0231.

Brusatte SL, Butler RJ, Prieto-Márquez A, Norell MA. 2012. Dinosaur morphological diversity and the end-Cretaceous extinction. Nature Communications 3:804.

Codron J, Botha-Brink J, Codron D, Huttenlocker AK, Angielczyk KD. 2017. Predator-prey interactions amongst Permo-Triassic terrestrial vertebrates as a deterministic factor influencing faunal collapse and turnover. Journal of Evolutionary Biology 30(1):40_ 54.

Day MO, Rubidge BS. 2018. Biesiespoort revisited: a case study on the relationship between tetrapod assemblage zones and Beaufort lithostratigraphy south of Victoria West. Palaeontologica africana 53:51-65.

Day MO, Smith RMH, Benoit J, Fernandez V, Rubidge B. 2018. A new species of burnetiid (Therapsida, Burnetiamorpha) from the early Wuchiapingian of South Africa and implications for the evolutionary ecology of the family Burnetiidae. Papers in Paleontology 4:453-475.

Day MO, Ramezani J, Bowring SA, Sadler PM, Erwin DH, Abdala F, Rubidge BS. 2015. When and how did the terrestrial mid-Permian extinction occur? Evidence from the tetrapod record of the Karoo Basin, South Africa. Proceedings of the Royal Society B 282:20150834.

Deeming D, Mayr G. 2018. Pelvis morphology suggests that early Mesozoic birds were too heavy to contact incubate their eggs. Journal of Evolutionary Biology 31:701-709. 
994 Felice RN, Watanabe A, Cuff AR, Noirault E, Pol D, Witmer LM, Norell MA, O’Connor

995

996

997

998

999

1000

1001

1002

1003

1004

1005

1006

1007

1008

1009

1010

1011

1012

1013

1014

1015

1016

OM, Goswami A. 2019. Evolutionary integration and modularity in the archosaur cranium. Integrative and Comparative Biology 59(2):371-382.

Francoy TM, Silva RAO, Nunes-Silva P, Menezes C, Imperatriz-Fonseca VL. 2009. Gender identification of five genera of stingless bees (Apidae, Meliponini) based on wing morphology. Genetics and Molecular Research 8(1):207-214.

Fröbisch J, Reisz RR. 2008. A new species of Emydops (Synapsida, Anomodontia) and a discussion of dental variability and pathology in dicynodonts. Journal of Vertebrate Paleontology 28(3):770-787.

Gastaldo RA, Kamo SL, Neveling J, Geissman JW, Bamford M, Looy CV. 2015. Is the vertebrate-defined Permian-Triassic boundary in the Karoo Bsin, South Africa, the terrestrial expression of the end-Permian marine event? Geology 43:939-942.

Grossnickle DM, Newham E. 2019. Therian mammals experience an ecomorphological radiation during the Late Cretaceous and selective extinction at the $\mathrm{K}-\mathrm{Pg}$ boundary. Proceedings of the Royal Society of London B 283:20160256.

Gunz P, Mitteroecker P, Neubauer S, Weber GW, Bookstein FL. 2009. Principles for the virtual reconstruction of hominin crania. Journal of Human Evolution 57:48-62.

Haughton SH. 1926. On Karroo Vertebrates from Nyasaland. Transactions of the Geological Society of South Africa 29:69-83.

Haughton SH, Brink AS. 1954. A bibliographical list of Reptilia from the Karroo Beds of Africa. Palaeontologia africana 2:1-187.

Hedrick BP, Dodson P. 2013. Lujiatun psittacosaurids: Understanding individual and taphonomic variation using 3D geometric morphometrics. PLoS ONE 8(8):e69265. 
1017 Hedrick BP, Schachner ER, Rivera G, Dodson P, Pierce SE. 2019. The effects of skeletal

1018

1019

1020

1021

1022

1023

1024

1025

1026

1027

1028

1029

1030

1031

1032

1033

1034

1035

1036

1037

1038

asymmetry on interpreting biologic variation and taphonomy in the fossil record. Paleobiology 45(1):154-166.

Hughes NC, Jell PA. 1992. A statistical/computer-graphic techniques for assessing variation in tectonically deformed fossils and its application to Cambrian trilobites from Kashmir. Lethaia 25:317-330.

Huene, F von. 1950. Die Theriodontier des ostafrikanischen Ruhuhu-Gebietes in der Tübinger Sammlung. Neues Jahrbuch für Geologie und Paläontologie Abhandlungen 92:47136.

Ivakhnenko MF, Golubev VK, Gubin YM, Kalandadze NN, Novikov IV, Sennikov AG, Rautian AS. 1997. Permian and Triassic tetrapods of Eastern Europe. Trudy Paleontologicheskogo Instituta, Akademiya Nauk SSSR. 268:1-216.

Jackson DA. 1993. Stopping rules in principal components analysis: a comparison of heuristical and statistical approaches. Ecology 74:2204-2214.

Jamniczky HA, Hallgrimsson B. 2009. A comparison of covariance structure in wild and laboratory muroid crania. Evolution 63(6):1540-1556.

Jasinoski SC, Abdala F. 2017. Cranial ontogeny of the Early Triassic basal cynodont Galesaurus planiceps. The Anatomical Record 300:353-381.

Kammerer CF. 2009. Cranial Disparity in the Non-Mammalian Synapsida. PhD Thesis, The University of Chicago, $649 \mathrm{pp}$.

Kammerer CF, Angielczyk KD. 2009. A proposed higher taxonomy of anomodont therapsids. Zootaxa 2018:1-24. 
1039 Kammerer CF, Deutsch M, Lungmus JK, Angielczyk KD. 2020. Dataset for: Effects of

1040

1041

1042

1043

1044

1045

1046

1047

1048

1049

1050

1051

1052

1053

1054

1055

1056

1057

1058

1059

1060

taphonomic deformation on geometric morphometric analysis of fossils: a case study using the dicynodont Diictodon feliceps (Therapsida: Anomodontia). Dryad Digital Repository, https://doi.org/10.5061/dryad.5tb2rbp1x

Kammerer CF, Viglietti PA, Hancox PJ, Butler RJ, Choiniere JN. 2019. A new kannemeyeriiform dicynodont (Ufudocyclops mukanelai, gen et sp. nov.) from Subzone C of the Cynognathus Assemblage Zone, Triassic of South Africa, with implications for biostratigraphic correlation with other African Triassic faunas. Journal of Vertebrate Paleontology e1596921.

Krone IW, Kammerer CF, Angielczyk KD. 2019. The many faces of synapsid cranial allometry. Paleobiology 45(4): 531-545. DOI: 1017/pab.2019.26.

Kemp TS. 1982. Mammal-Like Reptiles and the Origin of Mammals. New York: Academic Press, 363 pp.

King GM. 1993. How many species of Diictodon were there? Annals of the South African Museum. 102:303-325.

Kitching JW. 1977. The distribution of the Karroo vertebrate fauna. Bernard Price Institute for Palaeontological Research Memoir 1:1-131.

Klingenberg CP. 2008. MorphoJ. Faculty of Life Sciences, University of Manchester. http://www.flywings.org.uk/MorphoJ page.htm

Lalis A, Baylac M, Cosson JF. 2009. Cranial morphometric and fine scale genetic variability of two adjacent Mastomys natalensis (Rodentia: Muridae) populations. Acta Theriologica 54(2):171-181. 
1061 Lautenschlager S. 2016. Reconstructing the past: Methods and techniques for the digital

1062

1063

1064

1065

1066

1067

1068

1069

1070

1071

1072

1073

1074

1075

1076

1077

1078

1079

1080

1081

restoration of fossils. Royal Society Open Science 3:160342. DOI:

10.1098/rsos. 160342 .

Lungmus JK, Angielczyk KD. 2019. Antiquity of forelimb ecomorphological diversity in the mammalian stem lineage (Synapsida). Proceedings of the National Academy of Sciences 116:6903-6907.

Molnar JL, Pierce SE, Clack JA, Hutchinson JR. 2012. Idealized landmark-based geometric reconstructions of poorly preserved fossil material: a case study of an early tetrapod vertebra. Palaeontologia Electronica 15(1):1-18.

Motani R. 1997. New technique for retrodeforming tectonically deformed fossils, with an example for ichthyosaurian specimens. Lethaia 30:221-228.

\section{Moya-Sola S, Alba DM, Almecija S, Casanovas-Vilar I, Kohler M, De Esteban-Trivigno S,}

Robles JM, Galindo J, Fortuny J. 2009. A unique Middle Miocene European hominoid and the origins of the great ape and human clade. Proceedings of the National Academy of Sciences 106(24):9601-9606.

Navarro J, Kaliontzopoulou A, Gonzalez-Solis J. 2009. Sexual dimorphism in bill morphology and feeding ecology in Cory's shearwater (Calonectris diomedea). Zoology 112(2):128-138.

Olson EC. 1966. Community evolution and the origin of mammals. Ecology 47:291-302.

Owen R. 1876. Descriptive and Illustrated Catalogue of the Fossil Reptilia of South Africa in the Collection of the British Museum. London: Taylor and Francis. xii + 88 pp., 70 pls. 
1082 Pérez-Ben CM, Báez AM, Schoch RR. 2019. Morphological evolution of the skull roof in

1083

1084

1085

1086

1087

1088

1089

1090

1091

1092

1093

1094

1095

1096

1097

1098

1099

1100

1101

1102

1103

1104

temnospondyl amphibians mirrors conservative ontogenetic patterns. Zoological Journal of the Linnean Society. DOI: 10.1093/zoolinnean/zlz068

Pierce SE, Angielczyk KD, Rayfield EJ. 2008. Patterns of morphospace occupation and mechanical performance in extant crocodilian skulls: A combined geometric morphometric and finite element modeling approach. Journal of Morphology 269:840-864.

Polly PD, Stayton CT, Dumont ER, Pierce SE, Rayfield EJ, Angielczyk KD. 2016. Combining geometric morphometrics and finite element analysis with evolutionary modeling: towards a synthesis. Journal of Vertebrate Paleontology 36:4.

Price SA, Friedman ST, Corn KA, Martinez CM, Larouche O, Wainwright PC. 2019. Building a body shape morphospace of teleostean fishes, Integrative and Comparative Biology. DOI: 10.1093/icb/icz115.

Prothero DR, Sanchez F. 2008. Systematics of the leptaucheniine oreodonts (Mammalia: Artiodactyla) from the Oligocene and earliest Miocene of North America. pp. 335-356 in Lucas SG, Morgan GS, Spielmann JA, Prothero DR. (eds.) Neogene Mammals. Bulletin of the New Mexico Museum of Natural History and Science 44.

R Core Team. (2018). R: A language and environment for statistical computing. R Foundation for Statistical Computing, Vienna, Austria. https://www.R-project.org/.

Ramsay JG, Huber MI. 1983. The Techniques of Modern Structural Geology. Volume 1: Strain Analysis. London: Academic Press, xiii +307 pp.

Rasband WS. 1997-2009. ImageJ. U. S. National Institutes of Health, Bethesda, Maryland. http://rsb.info.nih.gov/ij/ 
1105 Rohlf FJ. 2010. tpsDig, Version 2.12. Department of Ecology and Evolution, State University of 1106 New York at Stony Brook, Stony Brook, NY.

1107 Romer AS, Price LI. 1940. Review of the Pelycosauria. Geological Society of America Special $1108 \quad$ Papers. 28: $\mathrm{x}+1-538$.

1109 Rubidge BS (ed.) 1995. Biostratigraphy of the Beaufort Group (Karoo Supergroup). South 1110 African Committee for Stratigraphy Biostratigraphic Series. No. 1.

1111 Rubidge BS. 2005. Re-uniting lost continents - Fossil reptiles form the ancient Karoo and their wanderlust. South African Journal of Geology 108:135-172.

1113 Rubidge BS, Sidor CA. 2001. Evolutionary patterns among Permo-Triassic therapsids. Annual Review of Ecology and Systematics 32:449-480.

Rubidge BS, Day MO, Barbolini N, Hancox PJ, Choiniere JN, Bamford MK, Viglietti PA, McPhee BW, Jirah S. 2016. Advances in nonmarine Karoo biostratigraphy: significance for understanding basin development. Pp. 141-149 in Linol B, De Wit, MJ (eds.) Origin and Evolution of the Cape Mountains and Karoo Basin. Springer, Switzerland, 193pp.

Sakamoto M, Ruta M. 2012. Convergence and divergence in the evolution of cat skulls: Temporal and spatial patterns of morphological diversity. PLoS ONE 7(7):e39752.

1124 Schlager S, Profico A, Vincenzo FD, Manzi G. 2018. Retrodeformation of fossil specimens based on 3D bilateral semi-landmarks: Implementation in the R package "Morpho." PLoS ONE 13(3):e0194073. 
1127 Sheets, HD. 2014. Integrated Morphometrics Package (IMP) 8. https://www.animal-

$1128 \quad$ behaviour.de/imp/

1129 Sidor CA. 2015. The first biarmosuchian from the upper Madumabisa Mudstone Formation (Luangwa Basin) of Zambia. Palaeontologia africana 49:1-7.

1131 Sidor CA, Smith RMH. 2007. A second burnetiamorph therapsid from the Permian Teekloof Formation of South Africa and its associated fauna. Journal of Vertebrate Paleontology 27:420-430.

1134 Smith RMH. 1993. Vertebrate taphonomy of Late Permian floodplain deposits in the southwestern Karoo Basin of South Africa. Palaios 8:45-67.

1136 Smith RMH. 1995. Changing fluvial environments across the Permo-Triassic boundary in the Karoo Basin, South Africa and possible causes of tetrapod extinctions. Palaeogeography, Palaeoclimatology, Palaeoecology 117:81-104.

1139 Smith R, Botha J. 2005. The recovery of terrestrial vertebrate diversity in the South African 1140 Karoo Basin after the end-Permian extinction. Comptes Rendus Palevol 4:623-636.

1141 Smith RMH, Botha-Brink J. 2014. Anatomy of a mass extinction: sedimentological and taphonomic evidence for drought-induced die-offs at the Permo-Triassic boundary in the main Karoo Basin, South Africa. Palaeogeography, Palaeoclimatology, Palaeoecology 396:99-118.

1145 Smith RMH, Rubidge BS, van der Walt M. 2012. Therapsid biodiversity patterns and environments of the Karoo Basin, South Africa. In: Chinsamy A, ed. Forerunners of mammals: radiation, histology, biology. Bloomington and Indianapolis: Indiana University Press, 223-246, 330 pp. 
1149 Stayton CT, Ruta M. 2006. Geometric morphometrics of the skull roof of stereospondyls

1150 (Amphibia: Temnospondyli). Palaeontology 49(2):307-337.

1151 Sullivan C, Reisz RR, Smith RMH. 2003. The Permian mammal-like herbivore Diictodon, the oldest known example of sexually dimorphic armament. Proceedings of the Royal Society of London. Series B 270:173-178.

Sullivan C, Reisz RR. 2005. Cranial anatomy and taxonomy of the Late Permian dicynodont Diictodon. Annals of Carnegie Museum 74(1):45-75.

Tallman M, Amenta N, Delson E, Frost SR, Ghosh D, Klukkert ZS, Morrow A, Sawyer GJ. 2014. Evaluation of a new method of fossil retrodeformation by algorithmic symmetrization: Crania of papionins (Primates, Cercopithecidae) as a test case. PLoS ONE 9(7):e100833.

Tankard A, Welsink H, Aukes P, Newton R, Stetter E. 2009. Tectonic evolution of the Cape and Karoo basins of South Africa. Marine and Petroleum Geology 26:1379-1412.

Tschopp E, Russo J, Dzemski G. 2013. Retrodeformation as a test for the validity of phylogenetic characters: An example from diplodocid sauropod vertebrae. Palaeontologia Electronica 16:1-23.

1165 Torres MAJ. 2009. Geometric morphometric analysis of intrapopulational variation in the carapace and telson of the Indo-Pacific mole crab, Hippa pacifica Dana, 1852 (Anomura: Hippidae) from Linamon, Lanao del Norte, Philippines. Asia Life Sciences 18(1):87-97.

Ward PD, Montgomery DR, Smith RMH. 2000. Altered river morphology in South Africa related to the Permian-Triassic extinction. Science 289:1740-1743. 
1171 Ward PD, Botha J, Buick R, De Kock MO, Erwin DH, Garrison G, Kirschvink J, Smith RMH. 2005. Abrupt and gradual extinction among Late Permian land vertebrates in the Karoo Basin, South Africa. Science 307:709-714.

1174 Webster M, Hughes NC. 1999. Compaction-related deformation in Cambrian olenelloid trilobites and its implications for fossil morphometry. Journal of Paleontology 73(2):355-371.

1177 Wellman HW. 1962. A graphical method for analyzing fossil distortion caused by tectonic deformation. Geological Magazine 99:348-352.

Young MT, Brusatte SL, Ruta M, Andrade MBD. 2010. The evolution of Metriorhynchoidea (Mesoeucrocodylia, Thalattosuchia): an integrated approach using geometric morphometrics, analysis of disparity, and biomechanics. Zoological Journal of the Biologists: A Primer. Amsterdam: Elsevier, 433 pp.

1185 Zelditch ML, Sheets HD, Fink WL. 2003. The ontogenetic dynamics of shape disparity. Paleobiology 29(1):139-156. 


\section{Table 1 (on next page)}

Simulation variables.

This is a chart reflecting the different variables within each group that the simulations were run. For each group, with the variables above set as listed for that group, the simulated data will face deformation for 16 different $\theta$ 's. 


\begin{tabular}{|l|c|c|c|c|}
\hline & $\begin{array}{c}\text { Percentage of deformed } \\
\text { specimens }\end{array}$ & Amplitude & Variation & Variation \\
\hline Group 1 & All & 1.0 & random & not selected \\
\hline Group 2 & $50 \%$ deformed & 1.0 & random & not selected \\
\hline Group 3 & $94 \%$ deformed & 1.0 & random & not selected \\
\hline Group 4 & All & 1.0 & $-45^{\circ}$ to $135^{\circ}$ & not selected \\
\hline Group 5 & All & 1.0 & $0^{\circ}$ to $90^{\circ}$ & not selected \\
\hline Group 6 & All & 0.95 to 1.0 & random & selected \\
\hline Group 7 & All & 1.0 to 1.05 & random & selected \\
\hline Group 8 & $94 \%$ deformed & 1.0 to 1.05 & $-45^{\circ}$ to $135^{\circ}$ & selected \\
\hline
\end{tabular}

3 Table 1. This is a chart reflecting the different variables within each group that the simulations 4 were run. For each group, with the variables above set as listed for that group, the simulated data 5 will face deformation for 16 different $\theta$ 's. 
Table 2 (on next page)

Types of deformation observed in Diictodon feliceps crania. 


\begin{tabular}{|l|l|l|}
\hline Type of Deformation & Number in Sample & Percent of Total \\
\hline Anteroposterior & 22 & 4.7 \\
\hline Dorsoventral & 149 & 32.1 \\
\hline Anterodorsal Shear & 15 & 3.2 \\
\hline Lateral & 165 & 35.6 \\
\hline Right/Left Shear & 29 & 6.3 \\
\hline Saddle-shape & 49 & 10.6 \\
\hline Undistorted & 27 & 5.8 \\
\hline Anteroventral Shear & 8 & 1.7 \\
\hline Total Lateral Specimens & $\mathbf{4 6 4}$ & 6.2 \\
\hline Anteroposterior & 23 & 3.0 \\
\hline Dorsoventral & 165 & 3.7 \\
\hline Anterodorsal Shear & 17 & 10.3 \\
\hline Lateral & 30 & \\
\hline Right/Left Shear & 50 & \\
\hline Saddle-shape & & \\
\hline Undistorted & & \\
\hline
\end{tabular}




\begin{tabular}{|l|l|l|}
\hline Anteroventral Shear & 10 & 2.0 \\
\hline Total Dorsal Specimens & $\mathbf{4 8 5}$ & \\
\hline Anteroposterior & 18 & 4.7 \\
\hline Dorsoventral & 131 & 33.8 \\
\hline Anterodorsal Shear & 15 & 3.9 \\
\hline Lateral & 120 & 31.0 \\
\hline Right/Left Shear & 25 & 6.46 \\
\hline Saddle-shape & $\mathbf{3 8 7}$ & 11.9 \\
\hline Undistorted & 25 & 6.46 \\
\hline Anteroventral Shear & 76 (5) & \\
\hline Total Dorsal-Complete & $\mathbf{3 8}$ & \\
\hline
\end{tabular}

1

2 Table 2. Types of deformation observed in Diictodon feliceps crania. 


\section{Figure 1}

Landmark configurations utilized in this study.

(A) Dorsal view and (B) lateral view landmarks shown on a largely undistorted skull of Diictodon feliceps (USNM 22949). After reflecting and averaging, the landmarks in the dorsal dataset correspond to landmarks 1-10 in (A). See text for details. Scale bar equals $5 \mathrm{~cm}$. Photos: Christian Kammerer. 

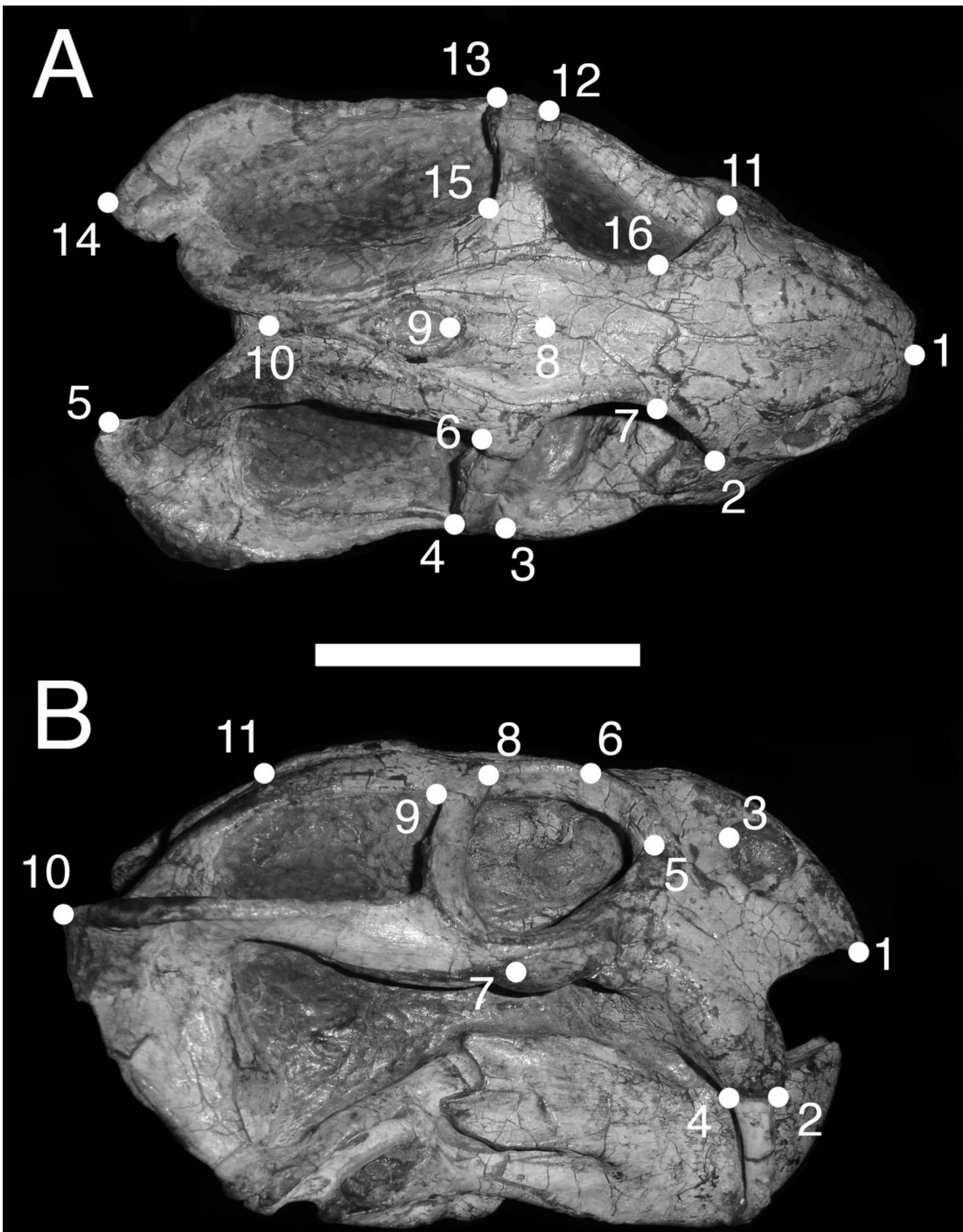
Figure 2

Typical styles of preservation in Diictodon feliceps.

(A) Dorsal and (B) right lateral (mirrored for comparison) views of an undistorted skull (USNM 22949). (C) Dorsal and (D) left lateral views of a laterally compressed skull (USNM 171064).

(E) Dorsal and (F) left lateral views of a dorsoventrally compressed skull (SAM-PK-K11558).

Scale bars equal $1 \mathrm{~cm}$. Photos: Christian Kammerer. 


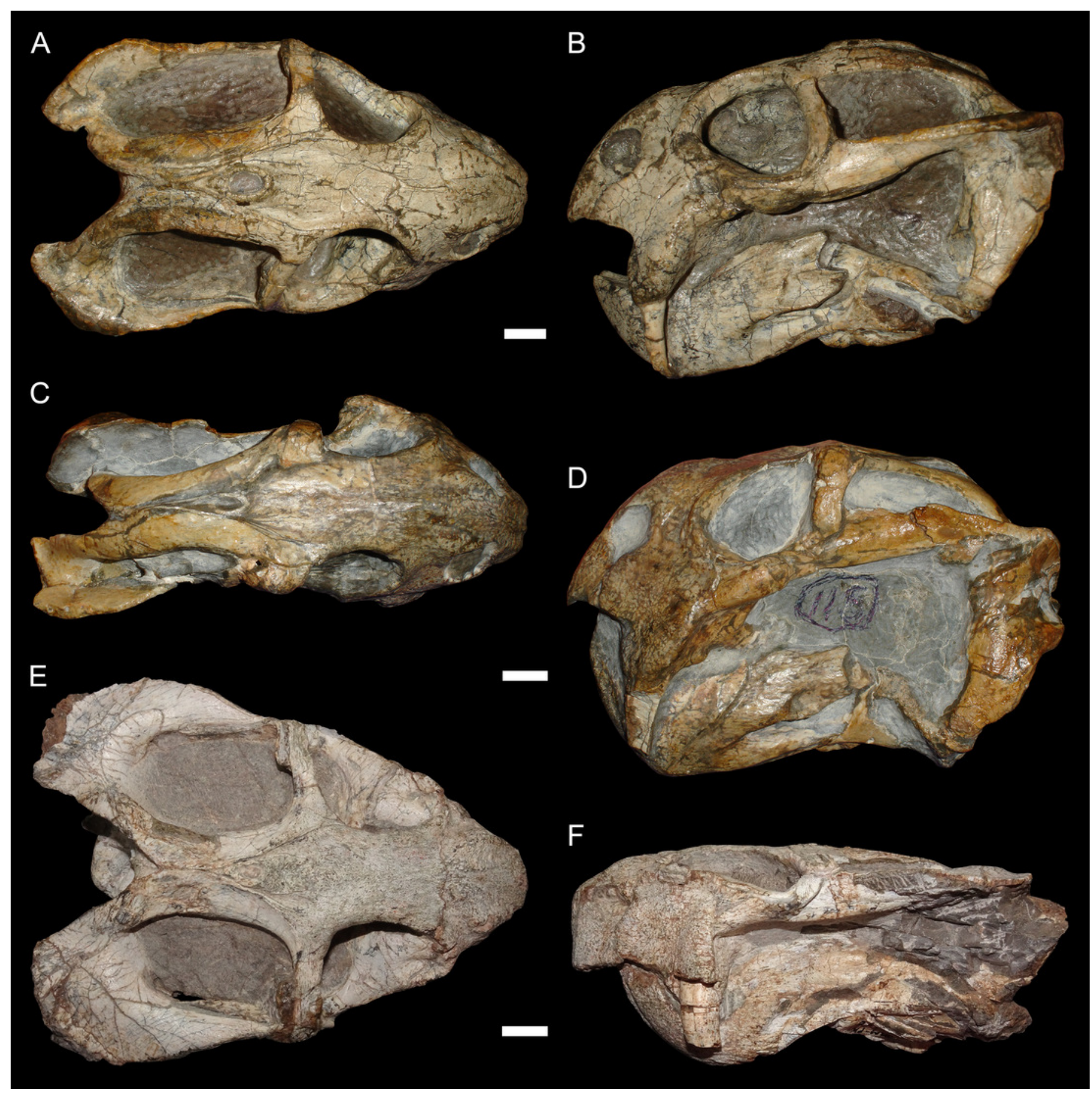




\section{Figure 3}

'Saddle-shape' deformation in therapsid skulls.

(A) Dorsal and (B) right lateal views of a skull of Diictodon feliceps (SAM-PK-K6838). Right lateral views of the theriodont therapsids (C) Ictidosuchoides (Therocephalia; CGS CM86-258) and (D) Cyonosaurus (Gorgonopsia; BP/1/137). Scale bars equal $1 \mathrm{~cm}$. Photos: Christian Kammerer.

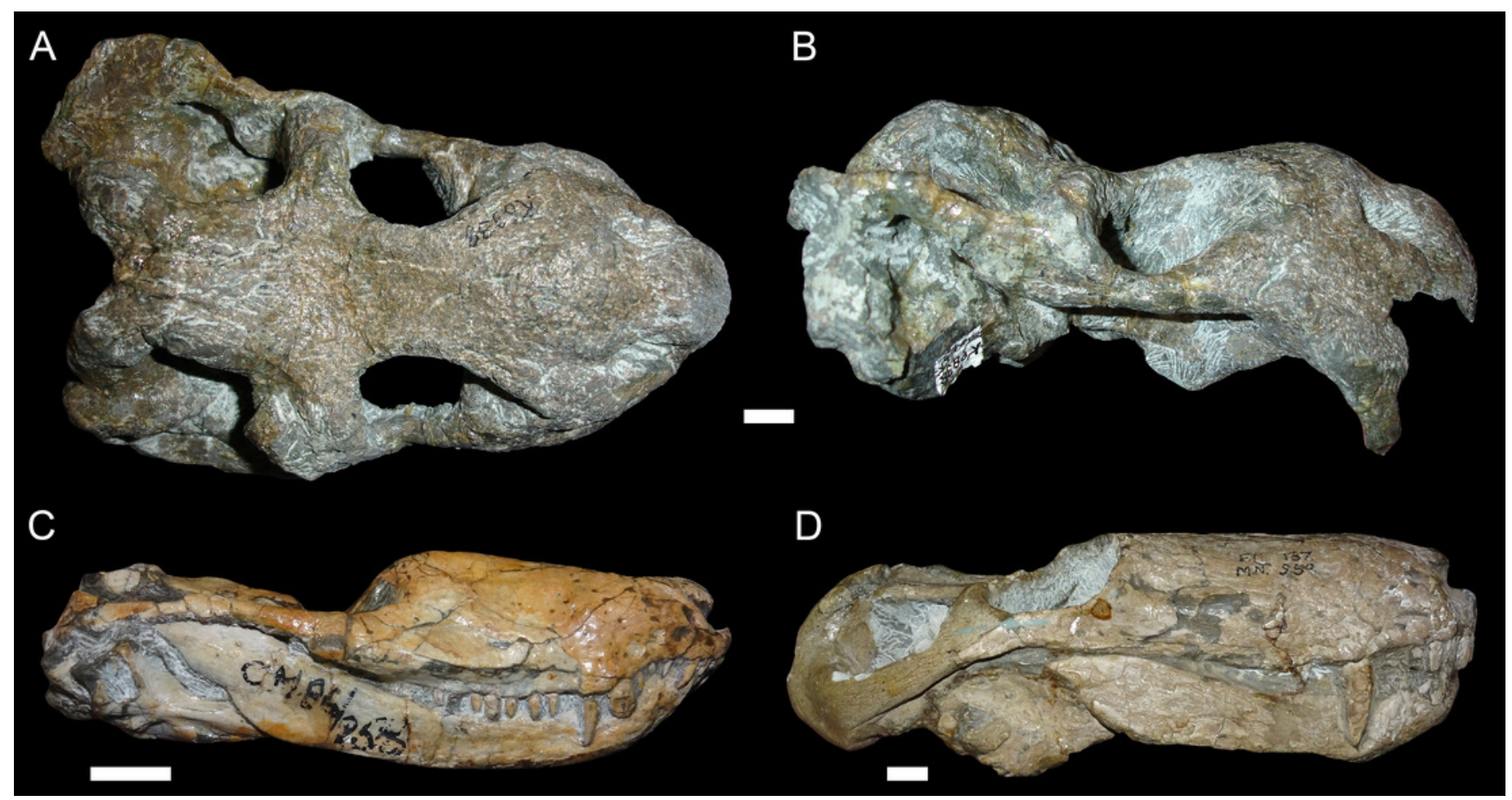


Figure 4

Anteroposterior deformation in Diictodon feliceps.

(A) Dorsal and (B) right lateral views of an anteroposteriorly compressed skull (USNM 22948). Scale bar equals $1 \mathrm{~cm}$. Photos: Christian Kammerer.

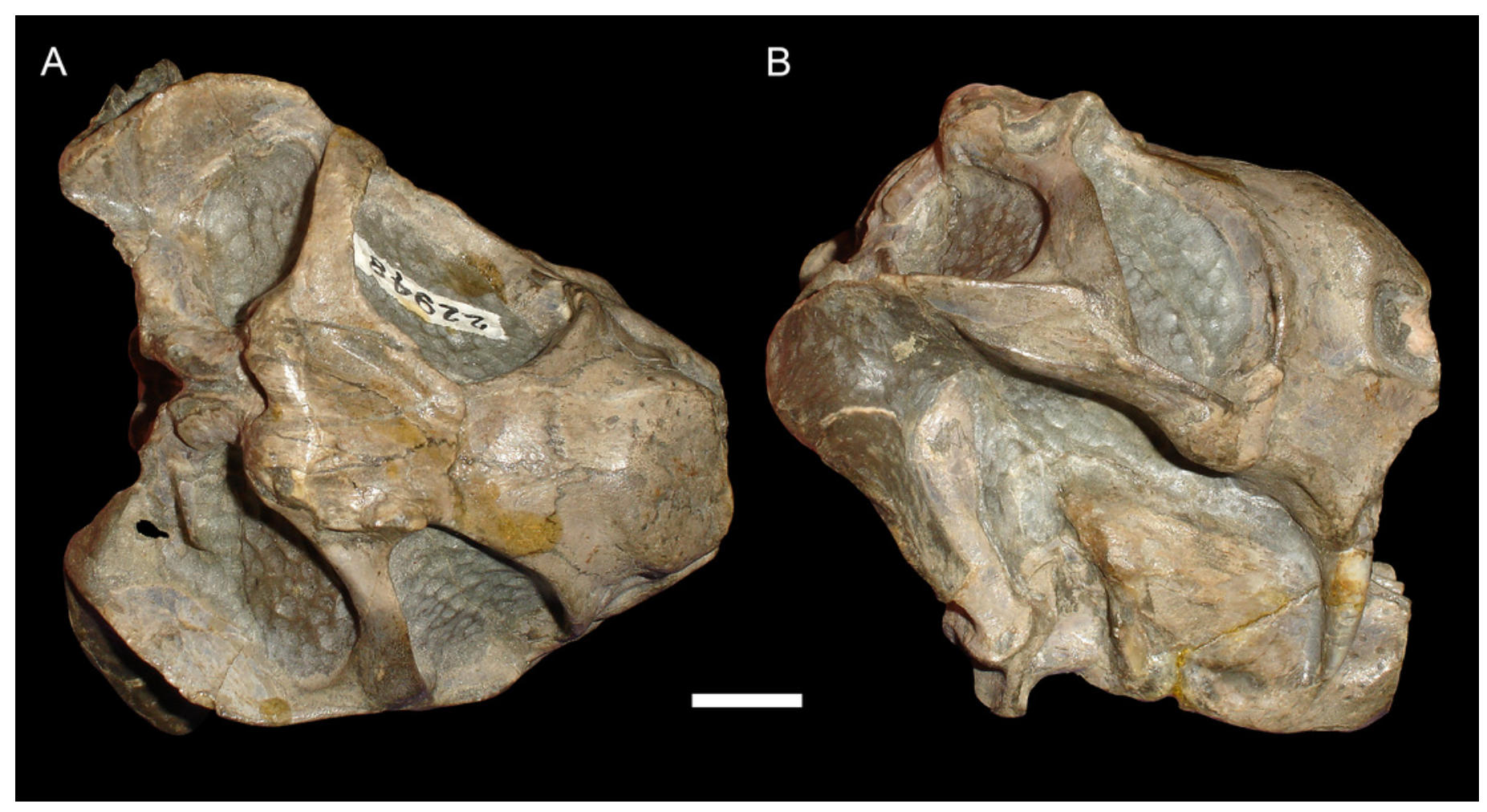




\section{Figure 5}

Sheared skulls in Diictodon feliceps.

(A) Dorsal and (B) right lateral views of an anterodorsally-sheared skull (BP/1/2317). (C)

Dorsal and (D) left lateral (mirrored for comparison) views of an anteroventrally-sheared skull (CGS R26). Scale bars equal $1 \mathrm{~cm}$. Photos: Christian Kammerer.

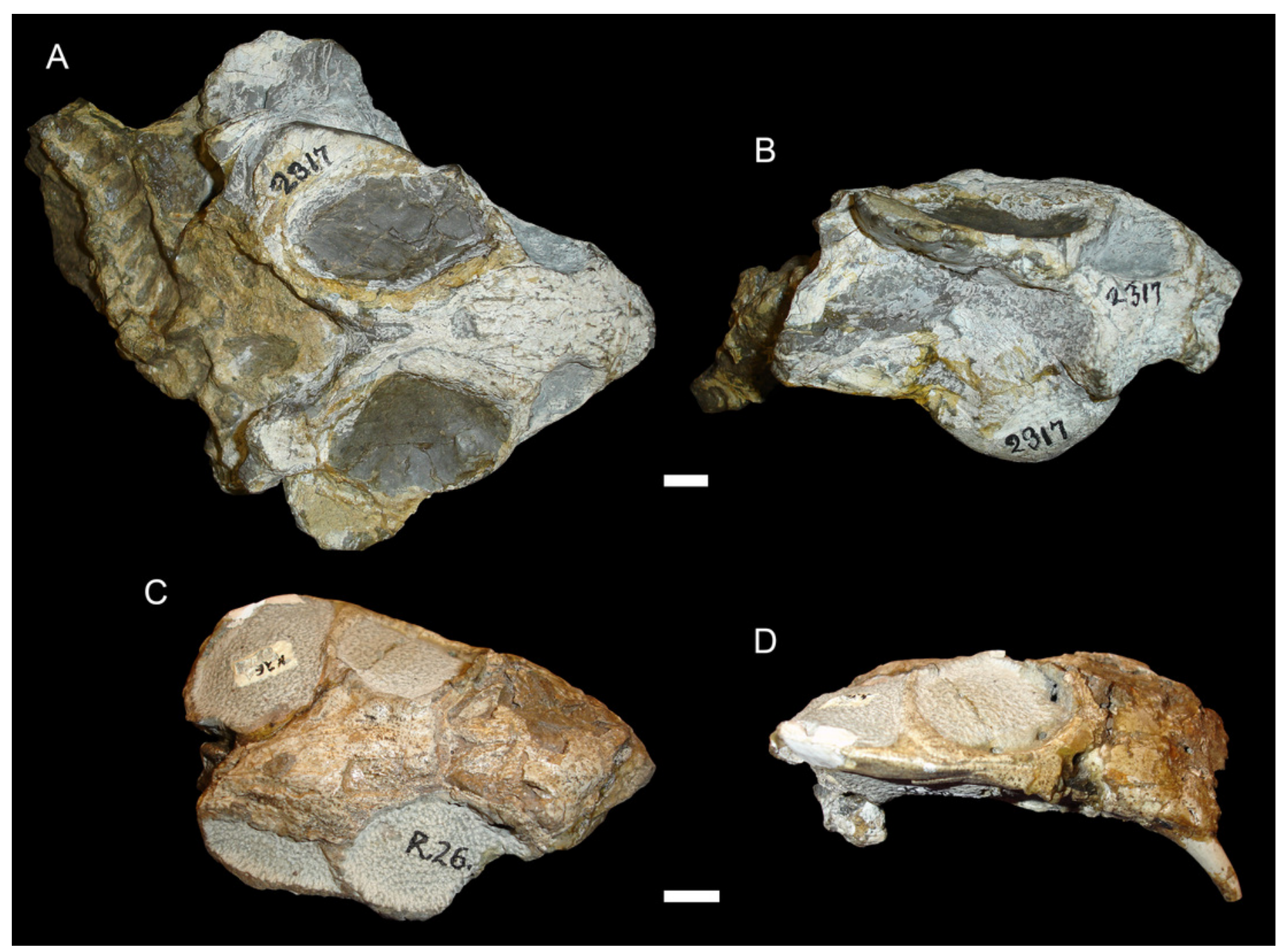




\section{Figure 6}

A sheared skull of Diictodon feliceps.

(A) Dorsal, (B) left lateral, and (C) right lateral views of a right/left sheared skull (USNM 25158). Scale bar equals $1 \mathrm{~cm}$. Photos: Christian Kammerer.

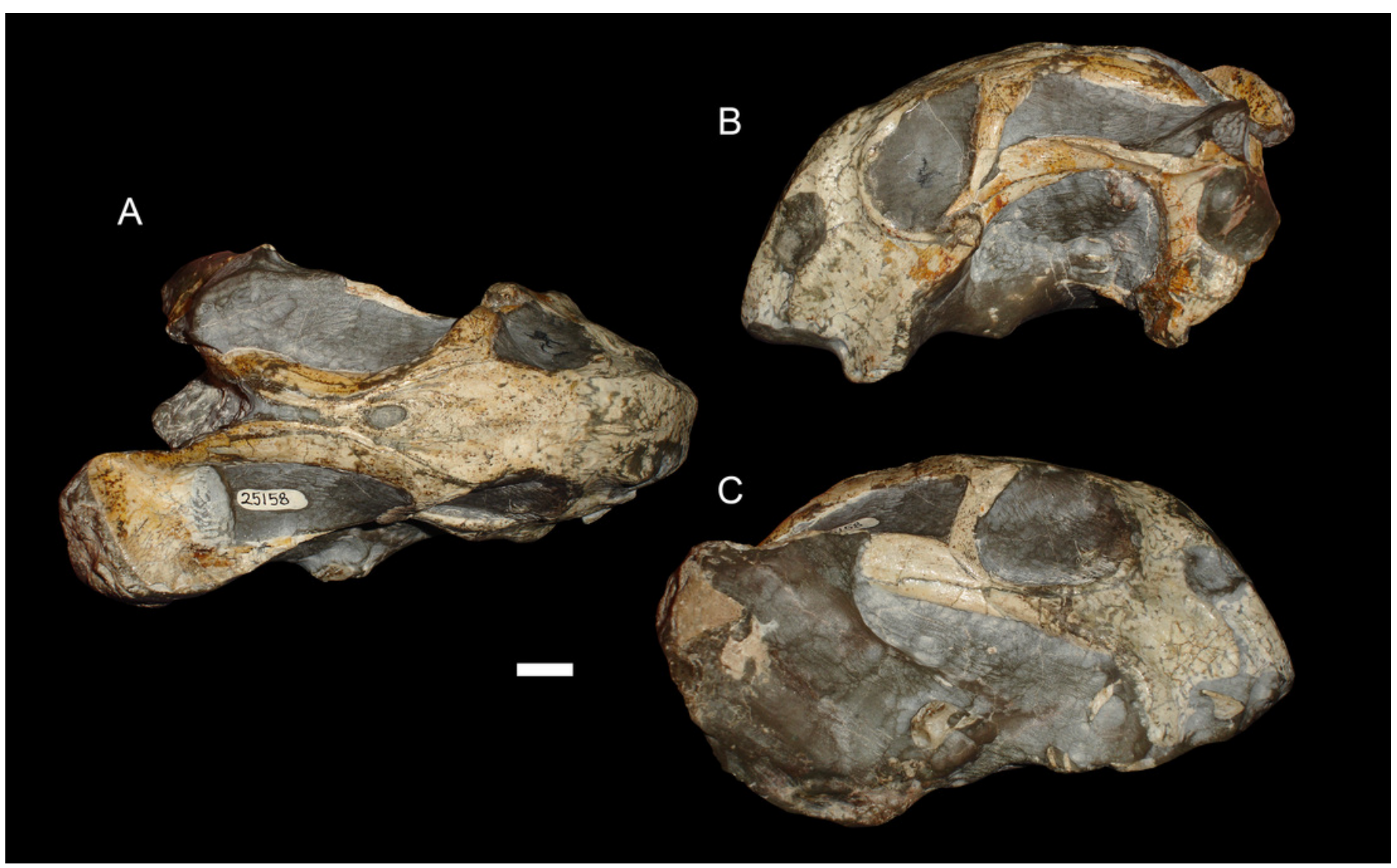


Figure 7

Morphological variation described by the two principal component (PC) axes from the empirical analysis of lateral Diictodon data.

The light blue wireframe represents the mean landmark configuration and the dark blue wireframe represents the changes in landmark position associated with a positive score on that PC. (A) PC 1. (B) PC2.
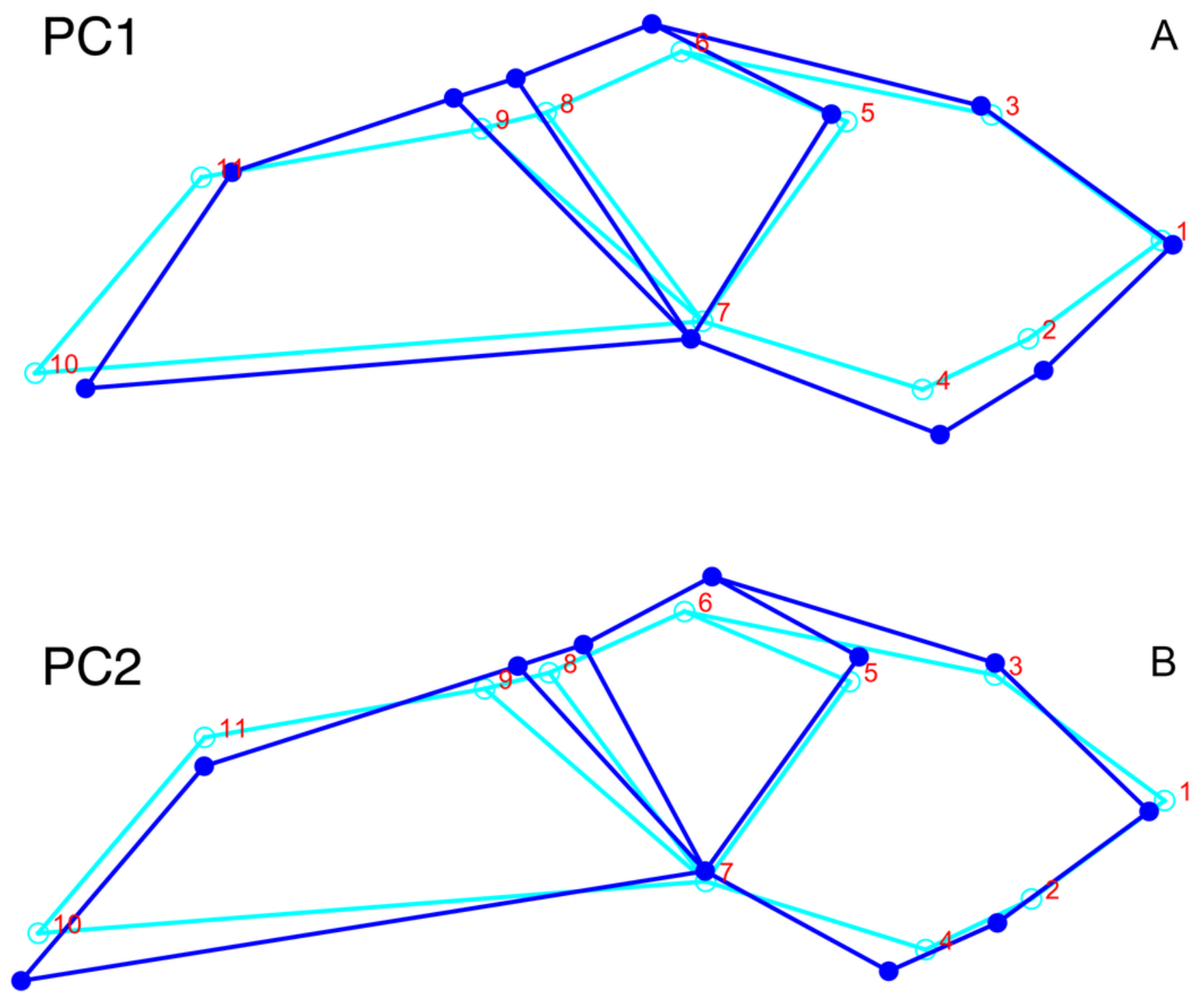
Figure 8

PC1 vs. PC2 morphospace plots of lateral empirical data.

Plots show variation in (A) sex, (B) deformation style, (C) size class, and (D) assemblage zone. Specimens for which sex or assemblage zone is unknown were included in the analysis but are uncolored in the plots. 

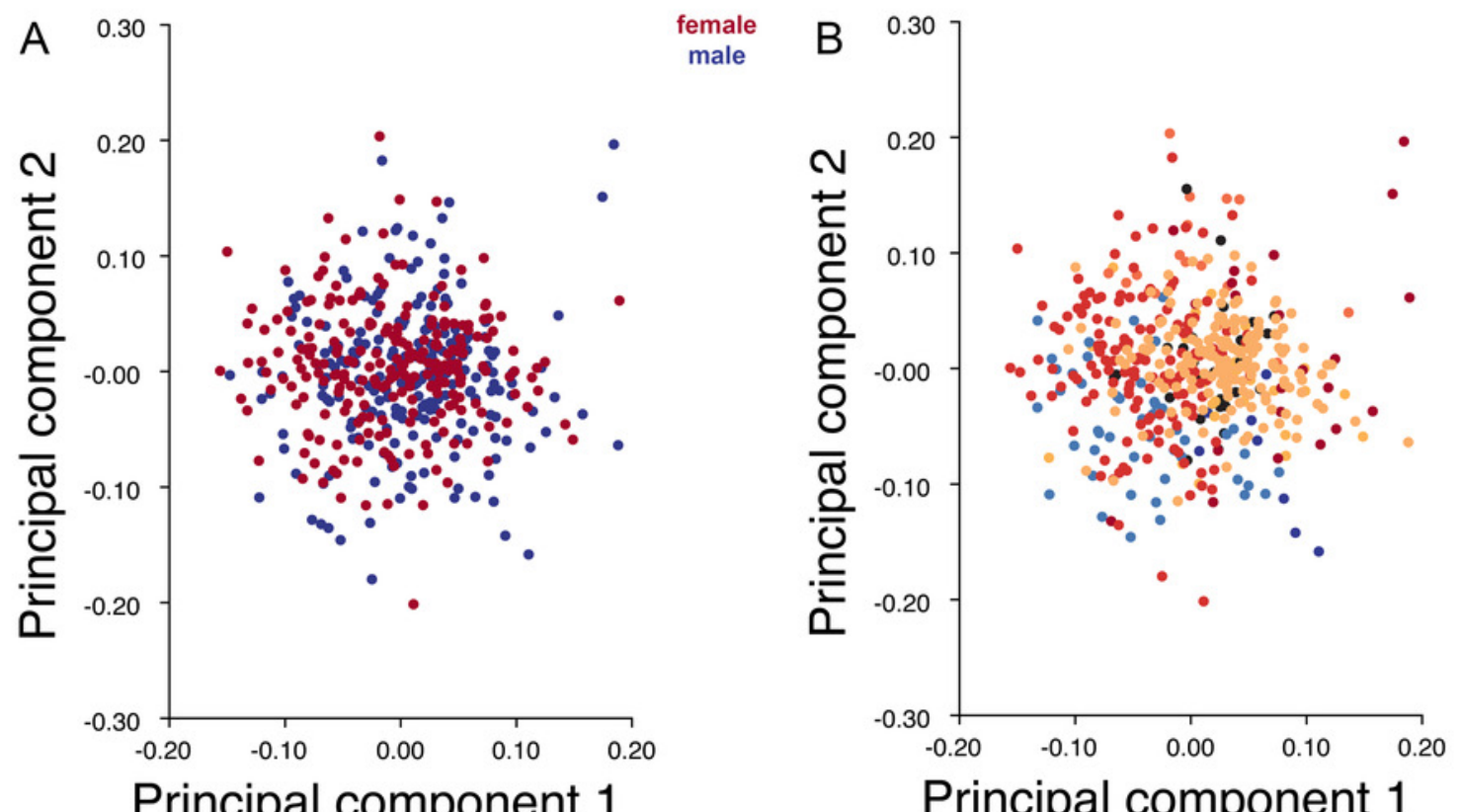

\author{
anteroposterior \\ dorsoventral \\ lateral \\ anterodorsal \\ anteroventral \\ right/left \\ saddle shape \\ undistorted
}

\title{
Principal component 1
}
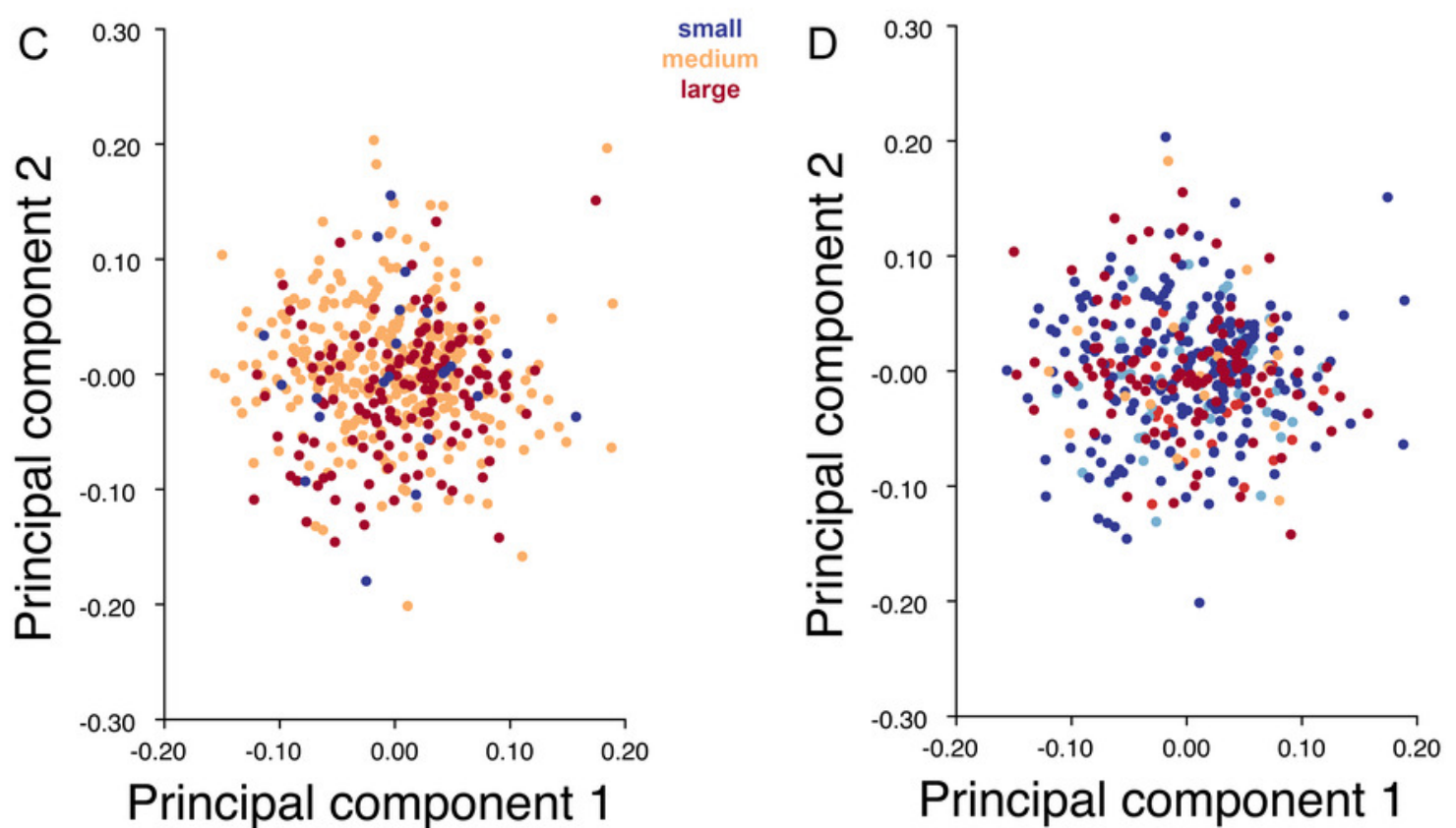

Daptocephalus AZ Cistecephalus AZ Tropidostoma AZ Pristerognathus AZ Tapinocephalus AZ

Principal component 1 
Figure 9

Morphological variation described by the two principal component (PC) axes from the empirical analysis of dorsal Diictodon data.

The light blue wireframe represents the mean landmark configuration and the dark blue wireframe represents the changes in landmark position associated with a positive score on that PC. (A) PC1. (B) PC2.
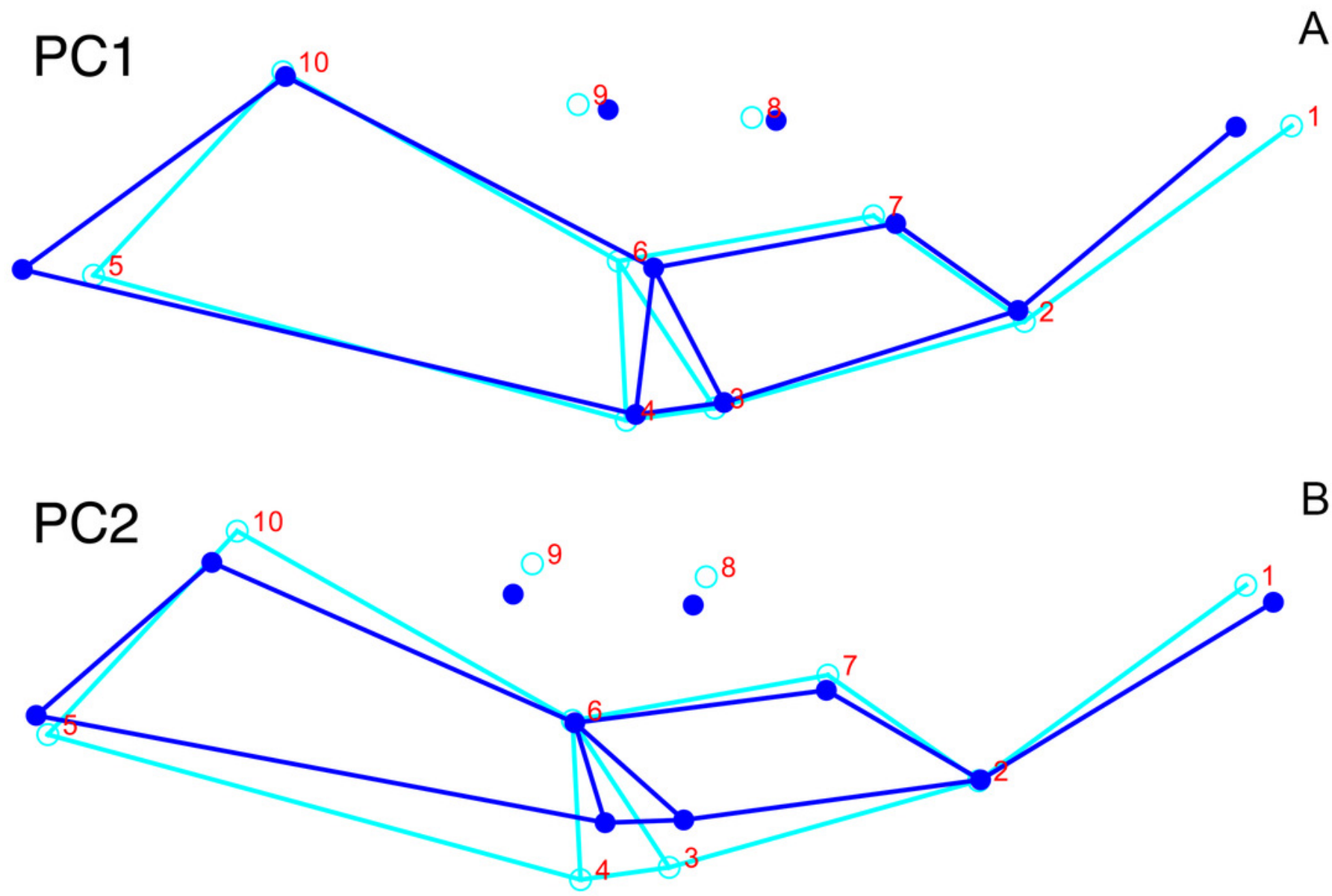
Figure 10

PC1 vs. PC2 morphospace plots of dorsal empirical data.

Plots show variation in (A) sex, (B) deformation style, (C) size class, and (D) assemblage zone. Specimens for which sex or assemblage zone is unknown were included in the analysis but are uncolored in the plots.
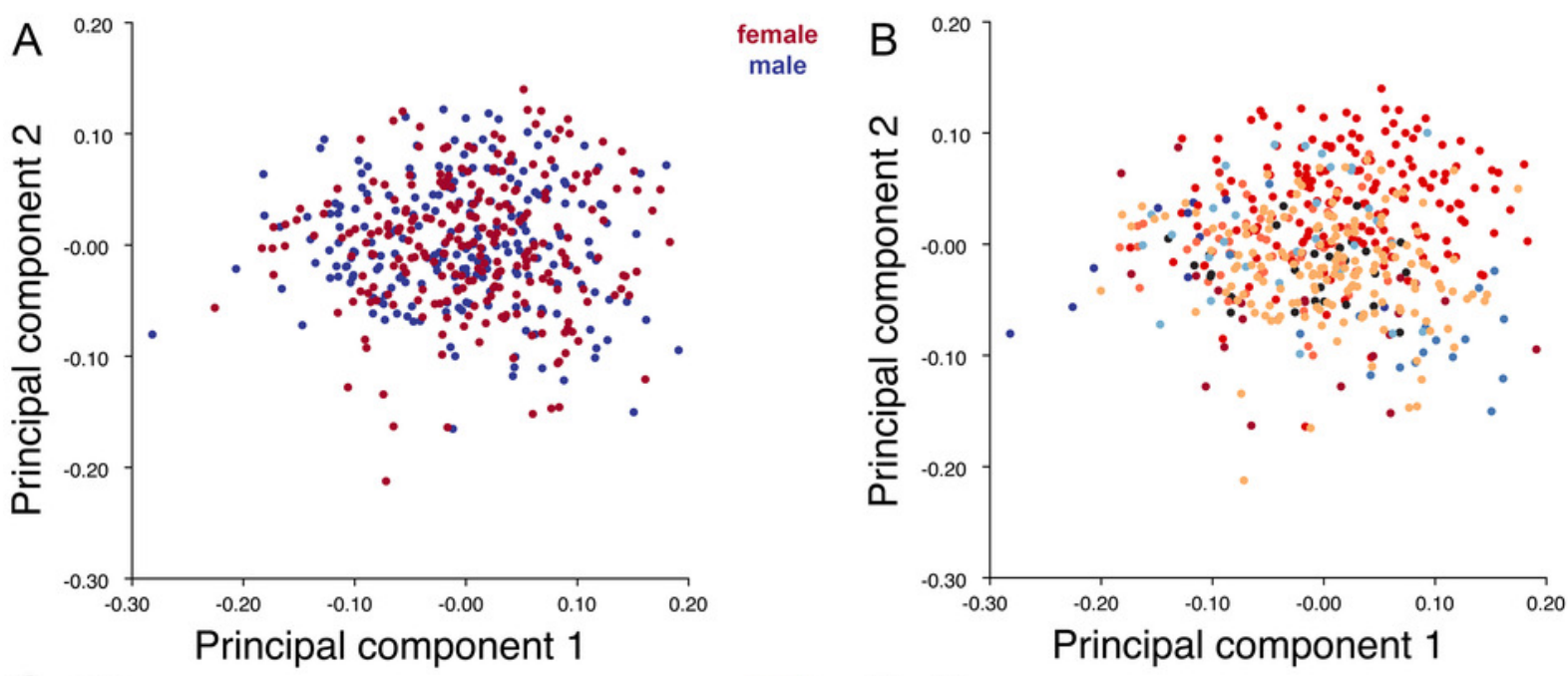

anteroposterior dorsoventral anterodorsal anteroventral right/left saddle shape undistorted
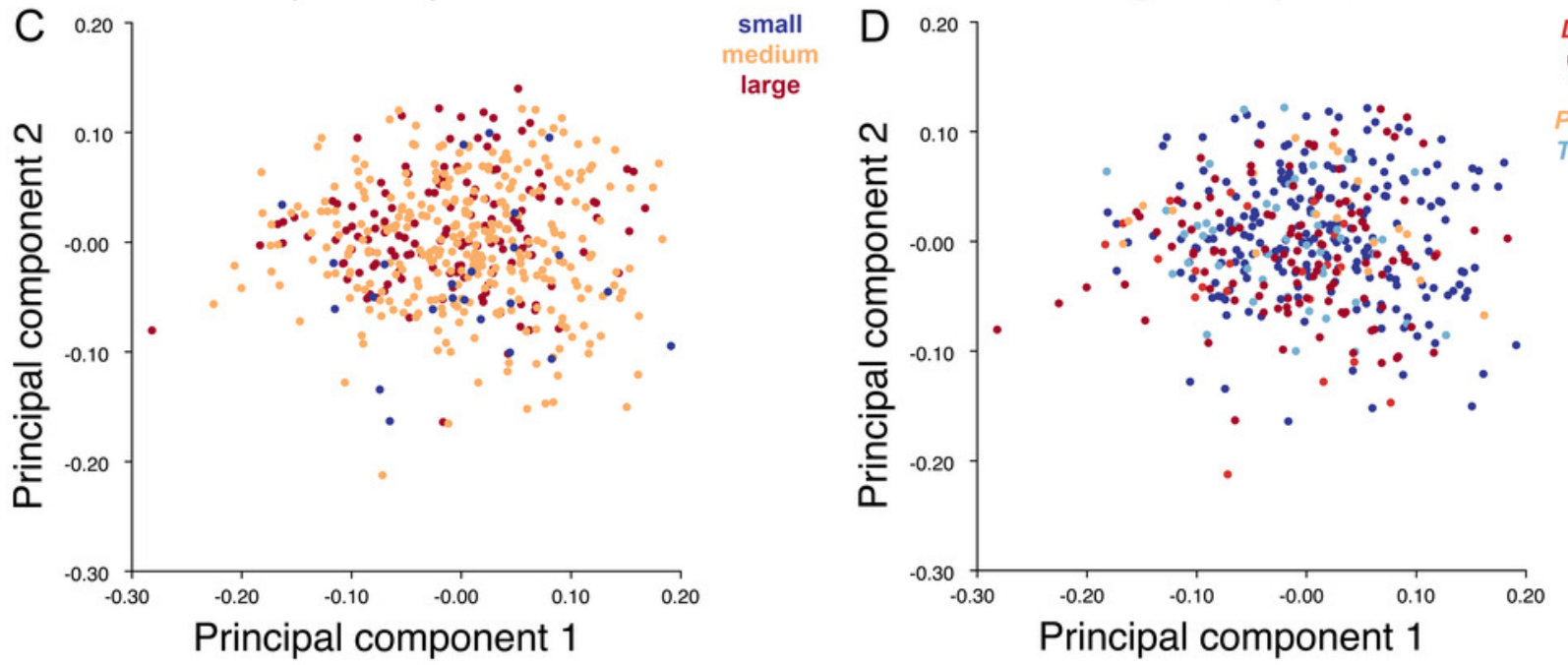

Daptocephalus AZ Cistecephalus AZ Tropidostoma AZ Pristerognathus AZ Tapinocephalus AZ 


\section{Figure 11}

Morphological variation described by the two principal component (PC) axes from the analysis of dorsal complete Diictodon data.

The light blue wireframe represents the mean landmark configuration and the dark blue wireframe represents the changes in landmark position associated with a positive score on that PC. (A) PC1. (B) PC2. 

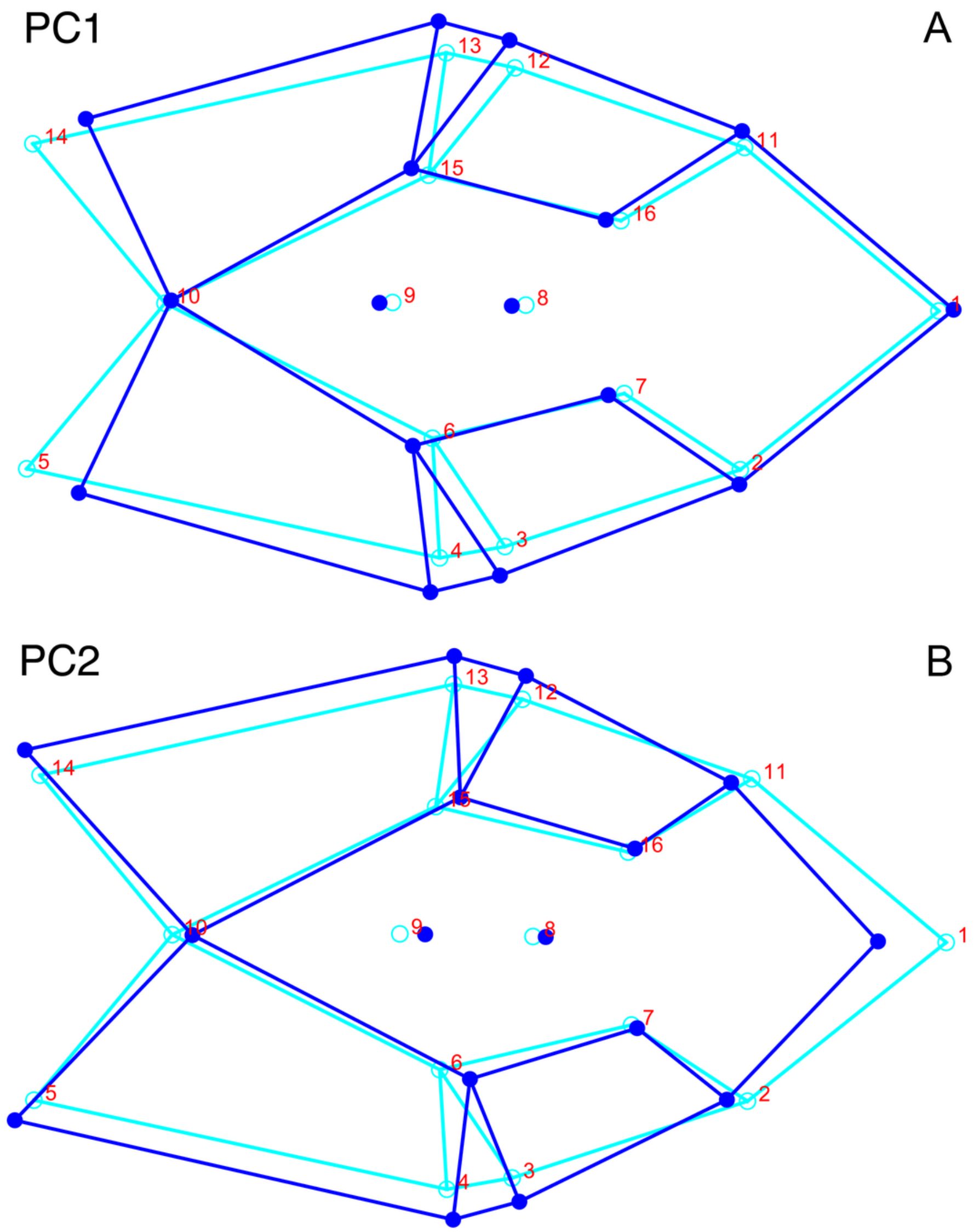

Peer] reviewing PDF | (2020:04:48101:1:1:NEW 4 Aug 2020) 


\section{Figure 12}

PC1 vs. PC2 morphospace plots of dorsal complete empirical data.

Plots show variation in (A) sex, (B) deformation style, (C) size class, and (D) assemblage zone. Specimens for which sex or assemblage zone is unknown were included in the analysis but are uncolored in the plots.
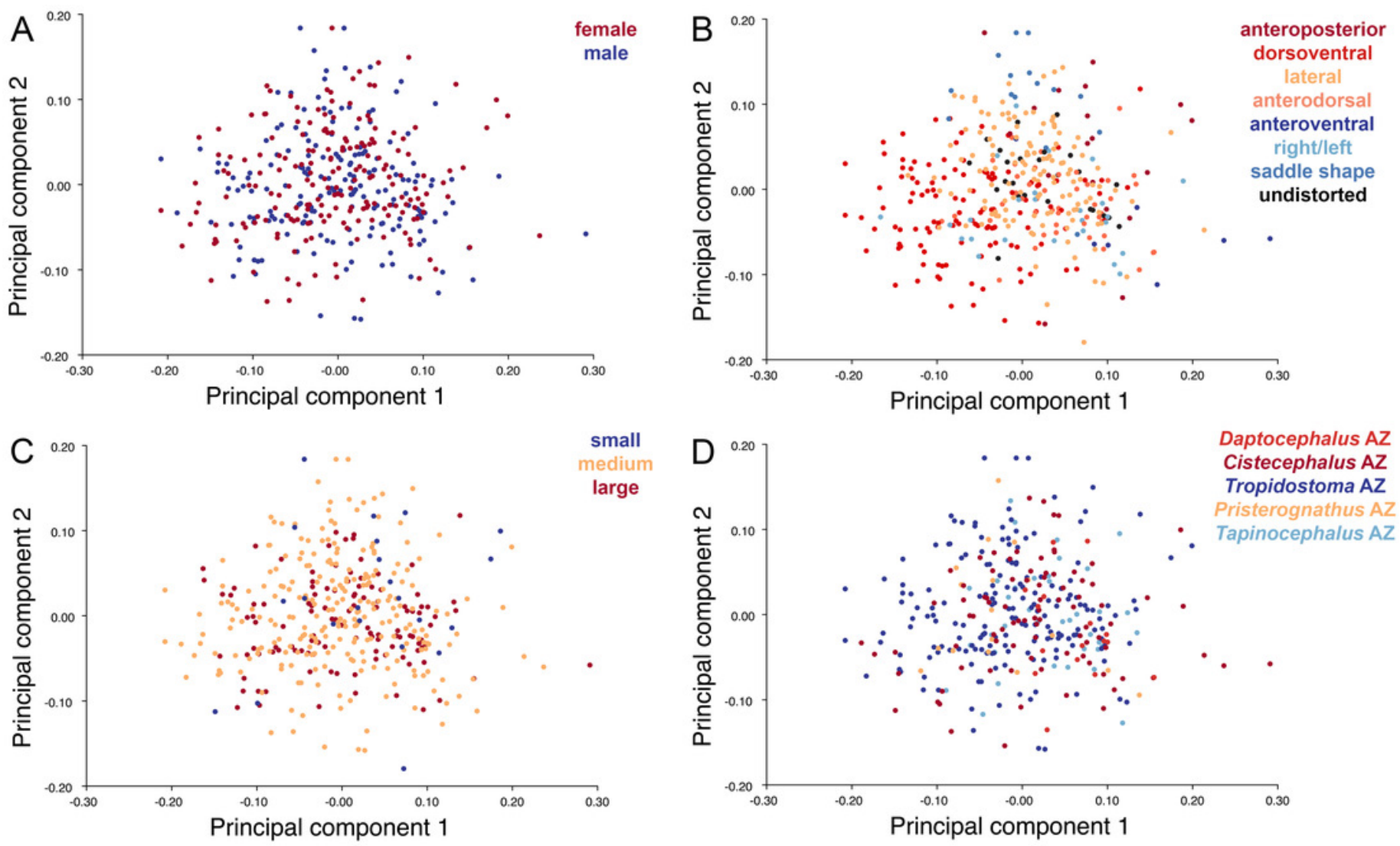


\section{Figure 13}

Morphological variation described by the four principal component (PC) axes from the analysis of lateral anomodont data.

The light blue wireframe represents the mean landmark configuration and the dark blue wireframe represents the changes in landmark position associated with a positive score on that PC. (A) PC1. (B) PC2. (C) PC3. (D) PC4.
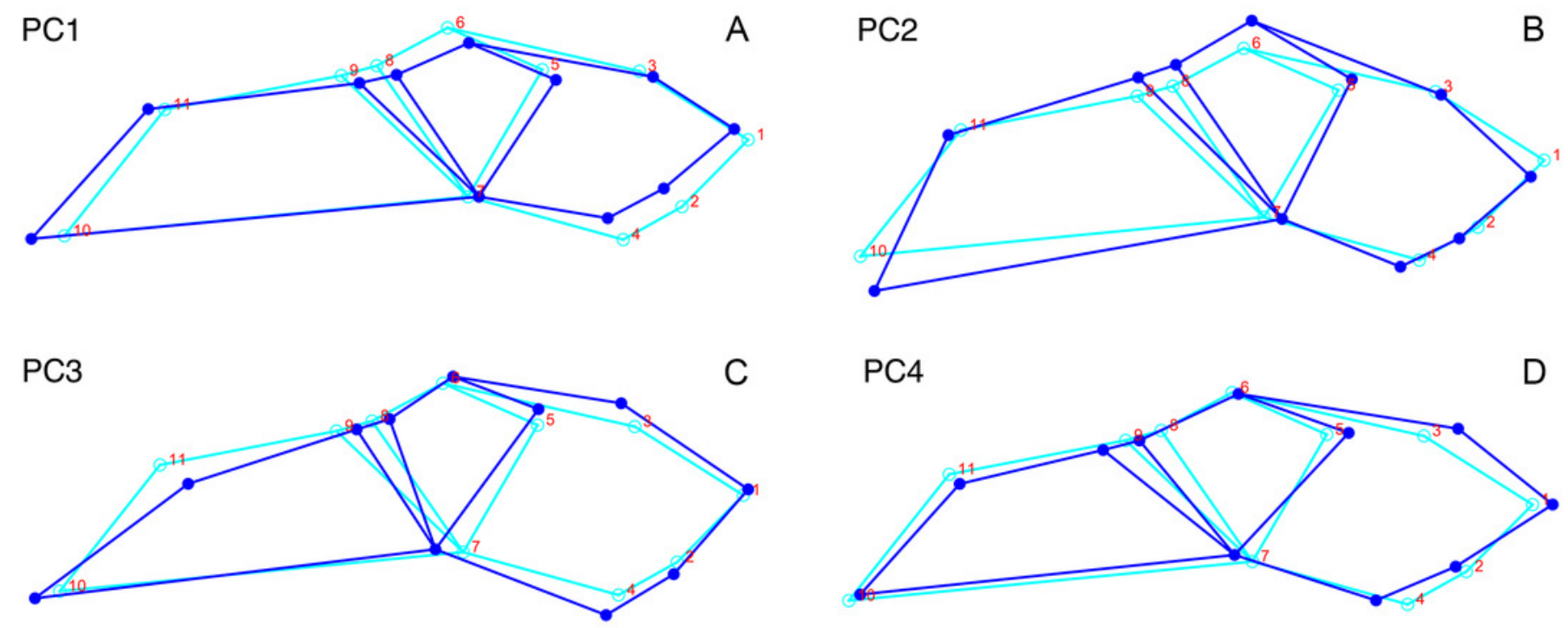
Figure 14

Anomodont lateral morphospace including only undistorted Diictodon.

The results of principal components analyses, showing the four primary axes of variation. (A)

PC1 vs. PC2. (B) PC1 vs. PC3. (C) PC1 vs. PC4. 

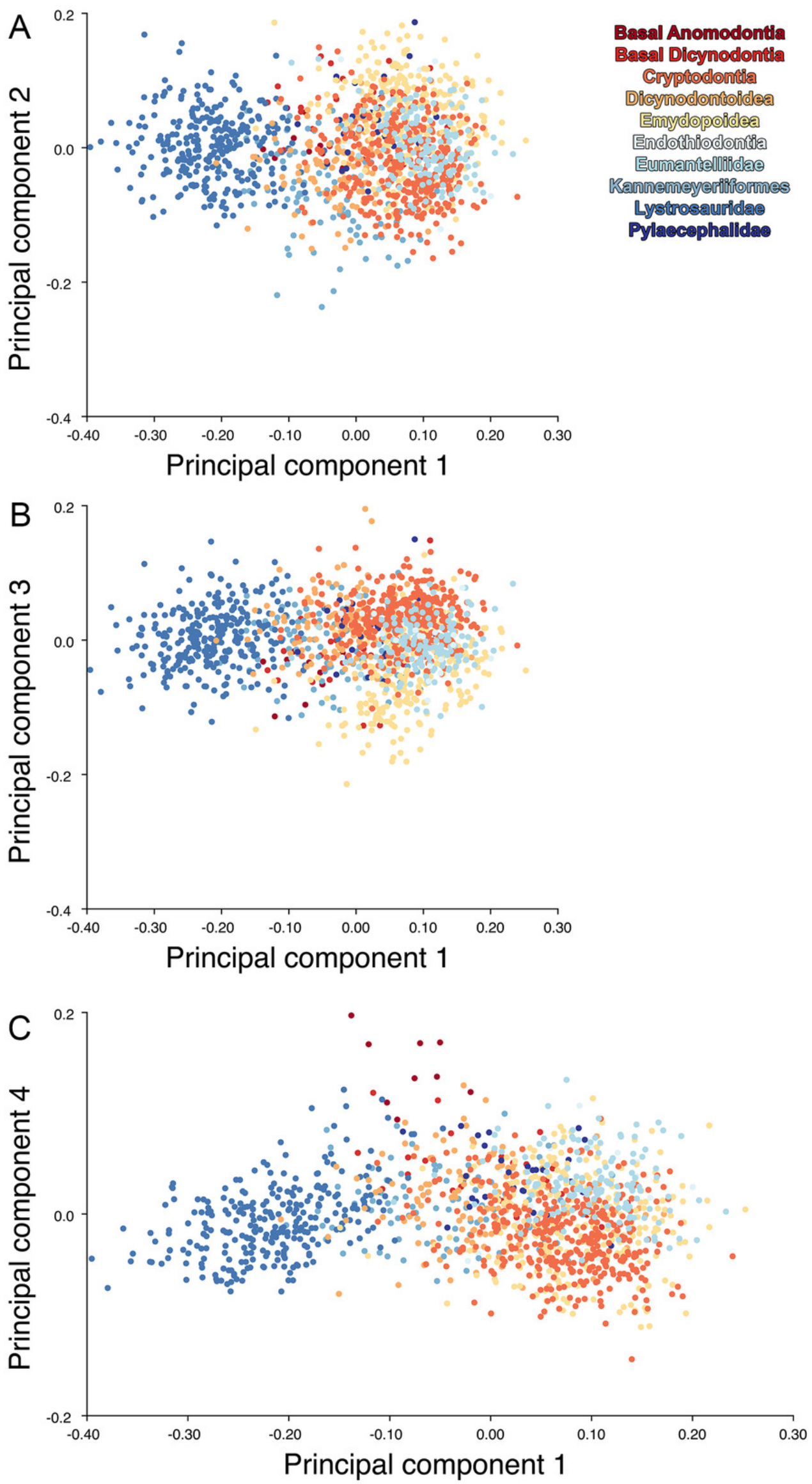

Peer] reviewing PDF | (2020:04:48101:1:1:NEW 4 Aug 2020) 


\section{Figure 15}

Anomodont lateral morphospace including deformed Diictodon.

The results of principal components analyses, showing the four primary axes of variation. (A)

PC1 vs. PC2. (B) PC1 vs. PC3. (C) PC1 vs. PC4. 


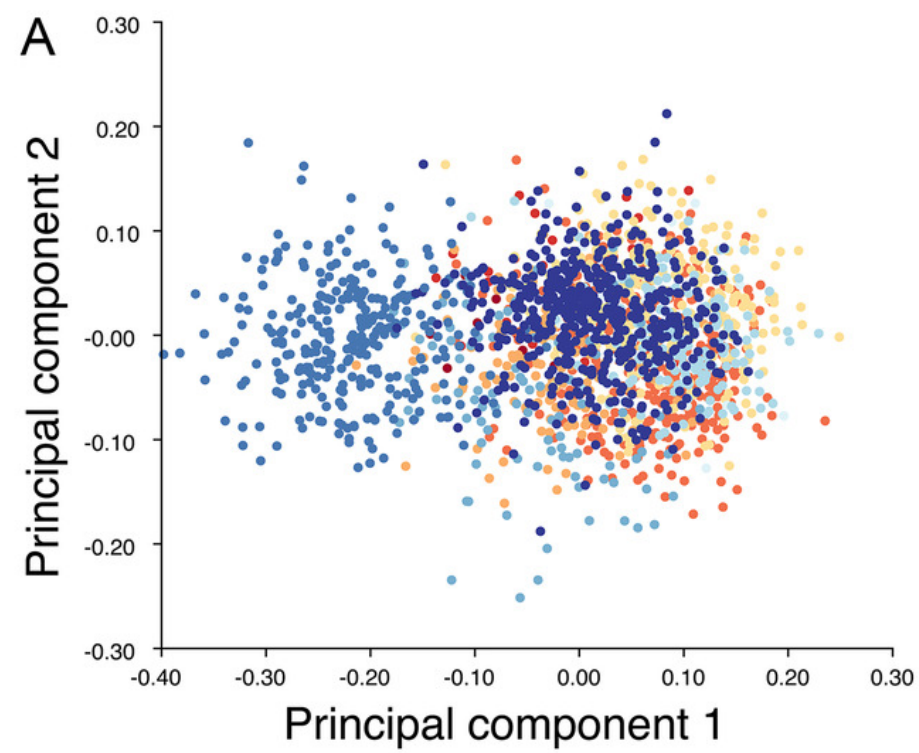

\author{
Basal Anomodontia \\ Basal Dicynodonte. \\ Cryyptodonte

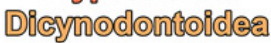 \\ 5mydopoideอ

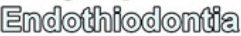

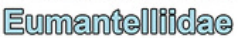

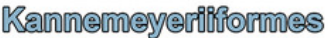 \\ Lystrosaurida. \\ Pylæacophalidå
}
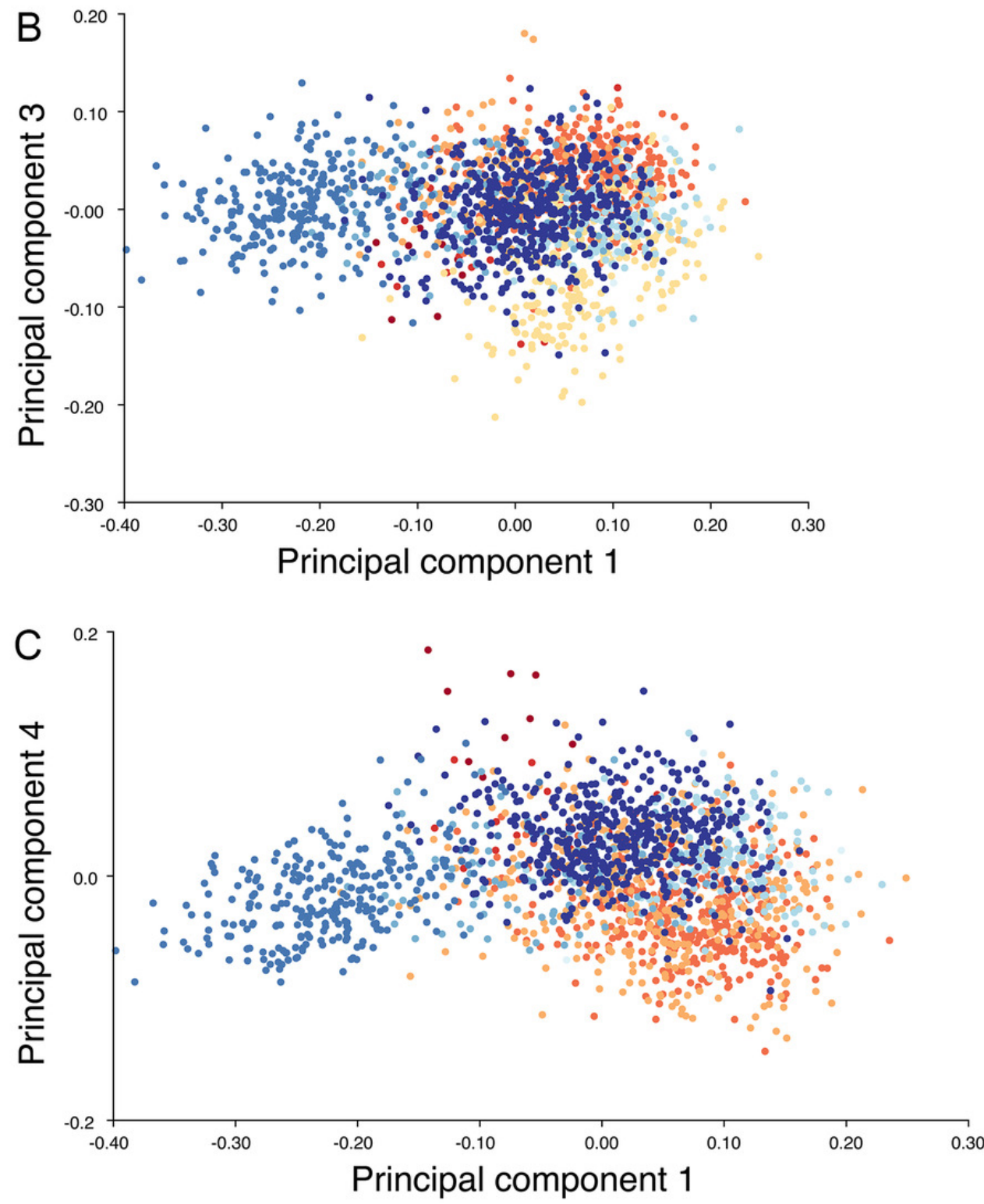


\section{Figure 16}

Position of Diictodon specimens (in blue) in anomodont lateral morphospace based on undistorted (left column) and all (right column) specimens.

(A) PC1 vs. PC2 including only undistorted Diictodon specimens. (B) PC1 vs. PC2 including deformed Diictodon specimens. (C) PC1 vs. PC3 including only undistorted Diictodon specimens. (D) PC1 vs. PC3 including deformed Diictodon specimens. (E) PC1 vs. PC4 including only undistorted Diictodon specimens. (F) PC1 vs. PC4 including deformed Diictodon specimens. 
Undistorted
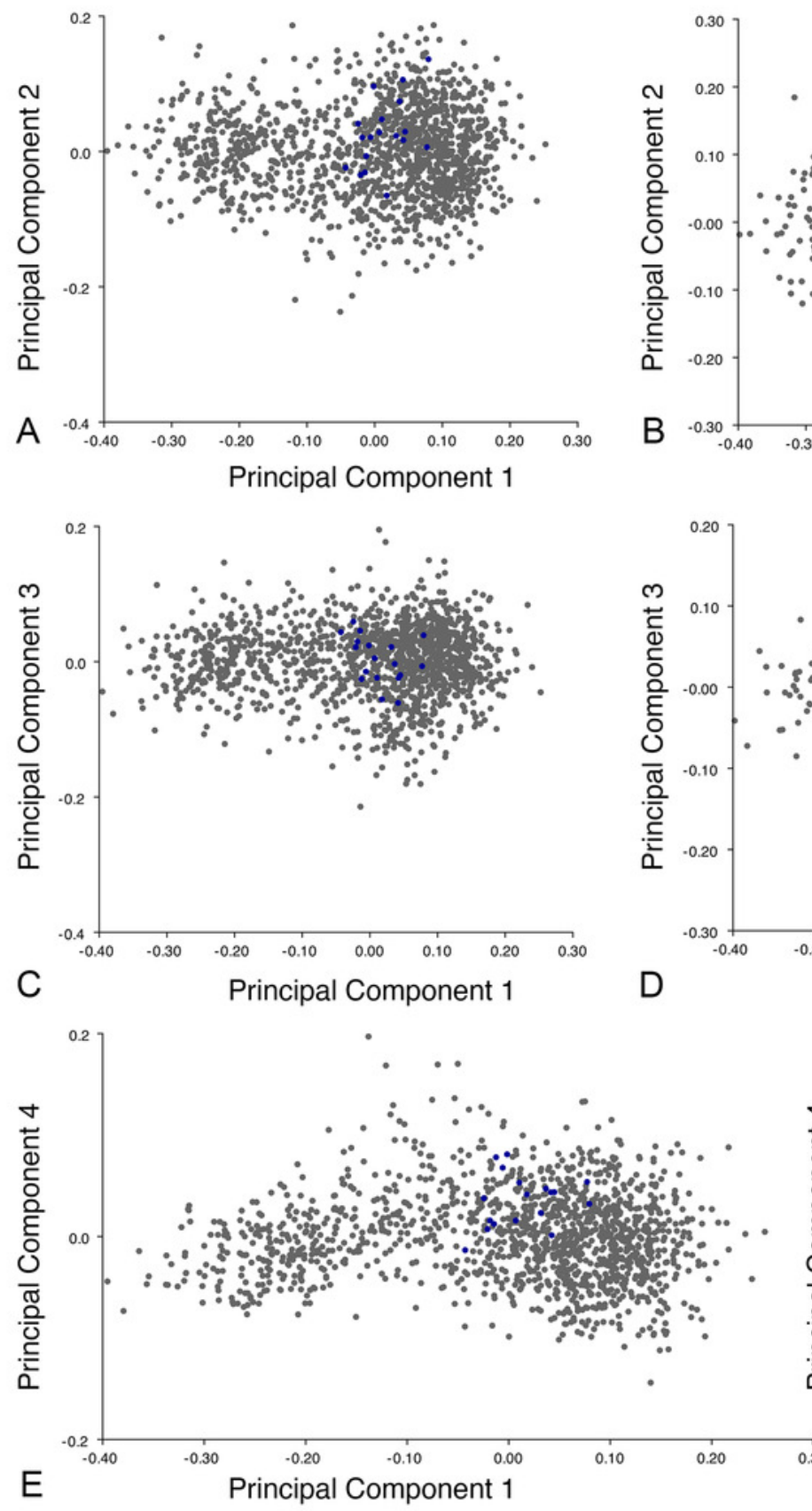

Deformed
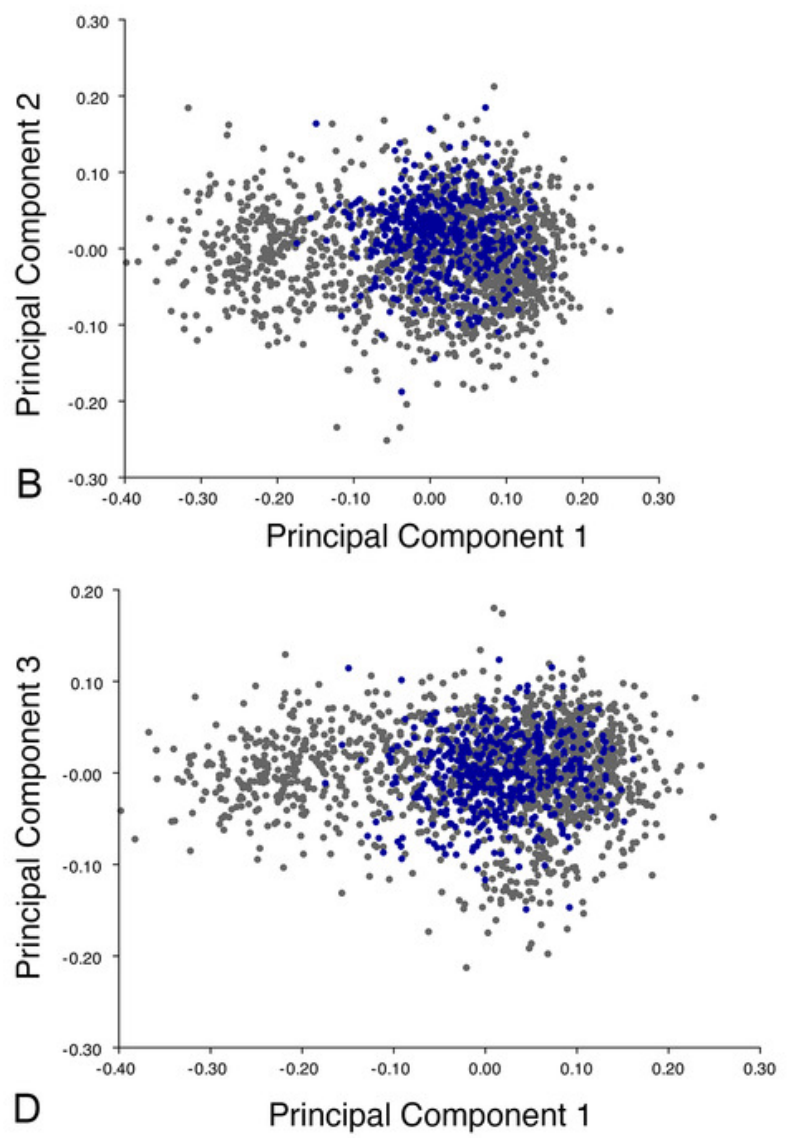

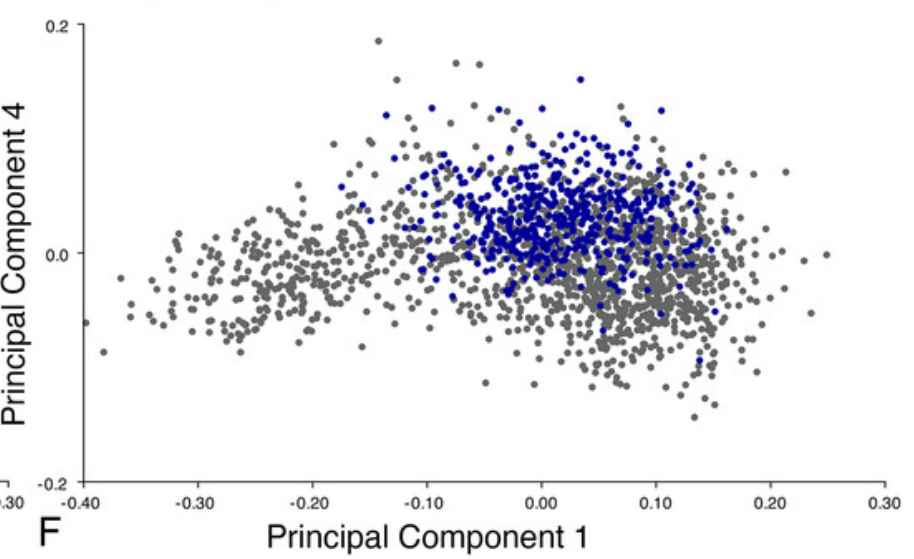


Figure 17

Morphological variation described by the four principal component (PC) axes from the analysis of dorsal complete anomodont data.

The light blue wireframe represents the mean landmark configuration and the dark blue wireframe represents the changes in landmark position associated with a positive score on that PC. (A) PC1. (B) PC2. (C) PC3. (D) PC4.
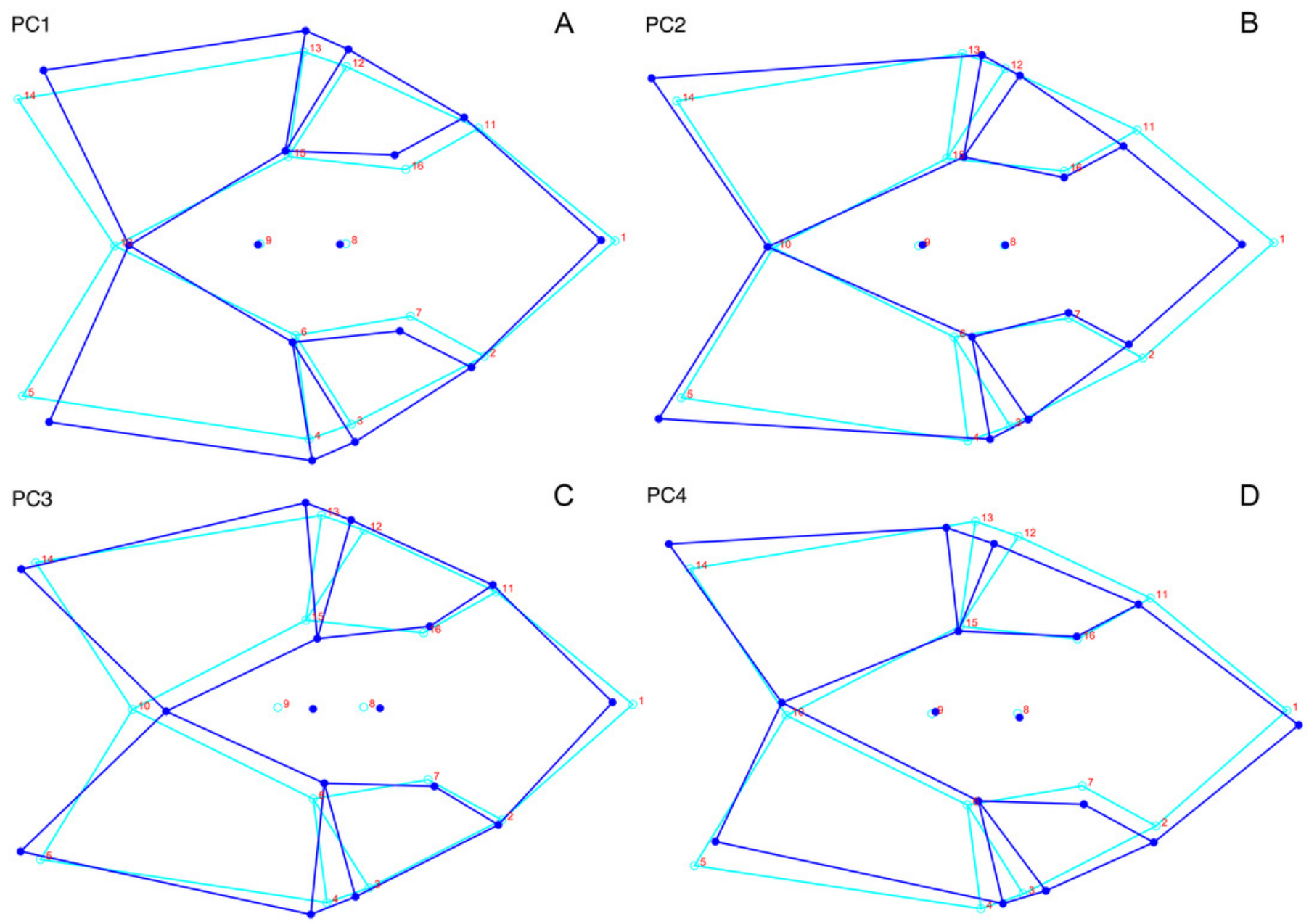


\section{Figure 18}

Anomodont dorsal complete morphospace including only undistorted Diictodon.

The results of principal components analyses, showing the four primary axes of variation. (A)

PC1 vs. PC2. (B) PC1 vs. PC3. (C) PC1 vs. PC4. 

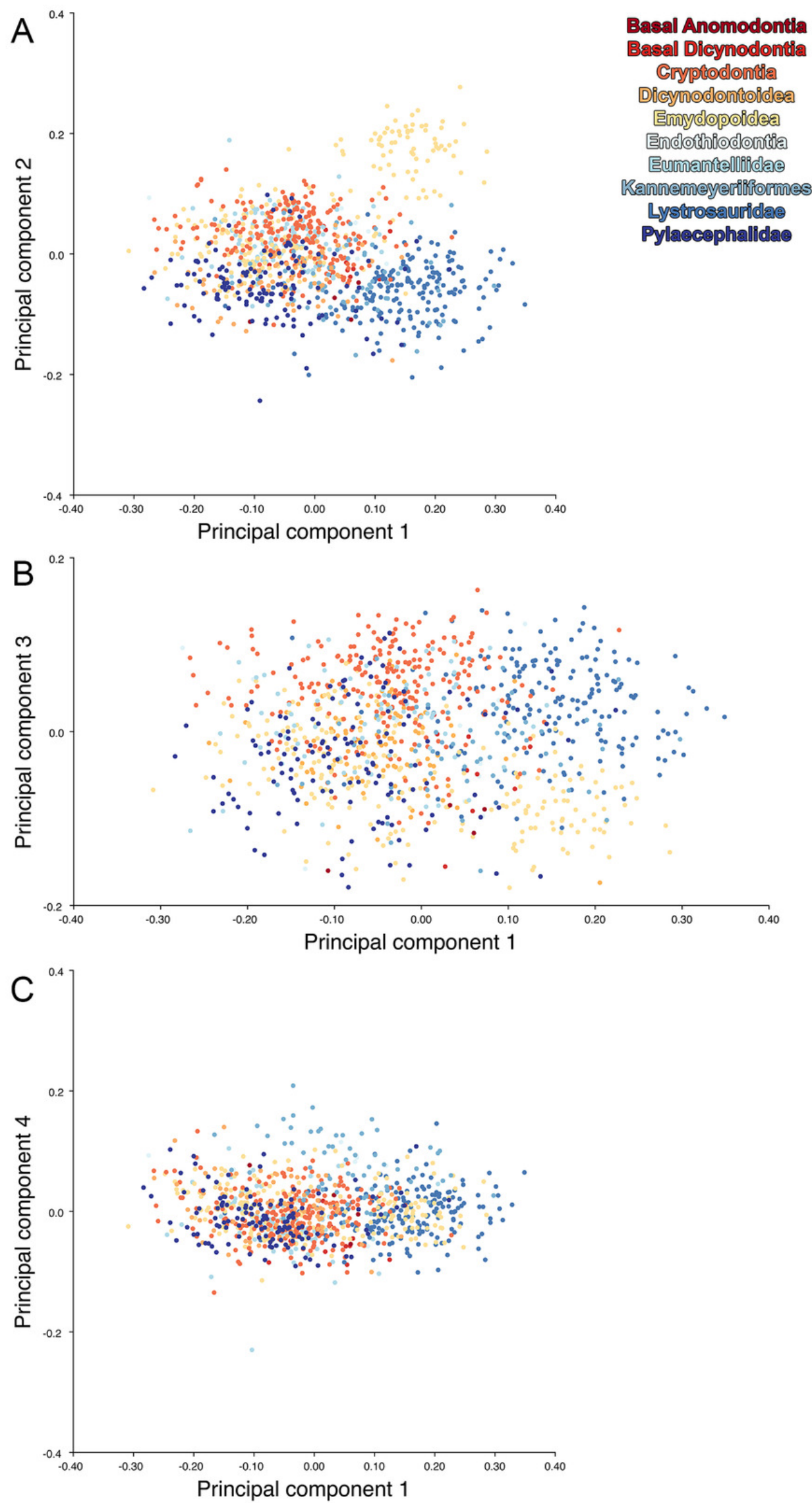

Peer] reviewing PDF | (2020:04:48101:1:1:NEW 4 Aug 2020) 


\section{Figure 19}

Anomodont dorsal complete morphospace including deformed Diictodon.

The results of principal components analyses, showing the four primary axes of variation. (A)

PC1 vs. PC2. (B) PC1 vs. PC3. (C) PC1 vs. PC4. 

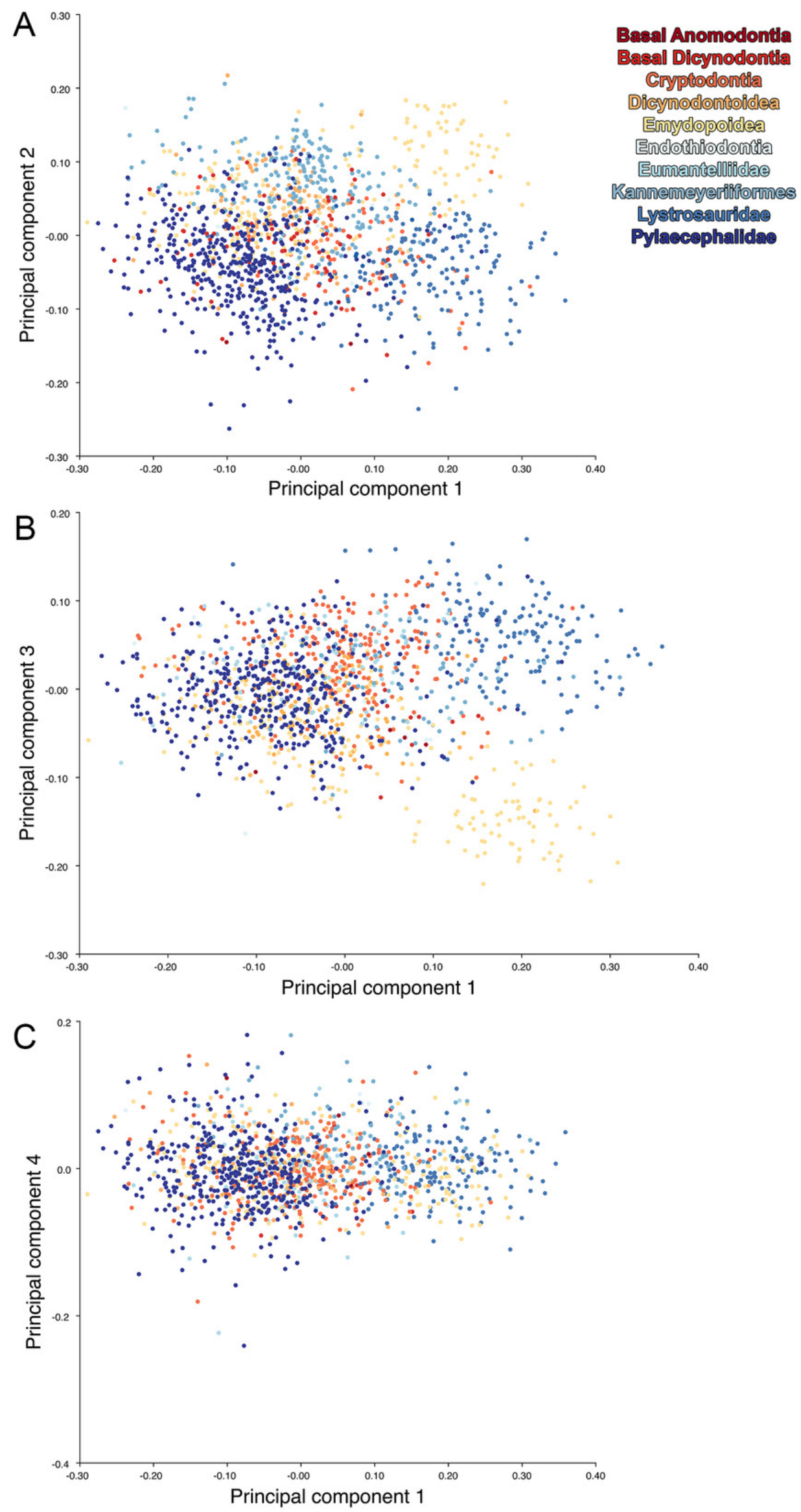

Peer) reviewing PDF | (2020:04:48101:1:1:NEW 4 Aug 2020) 


\section{Figure 20}

Position of Diictodon specimens (in blue) in anomodont dorsal complete morphospace based on undistorted (left column) and all (right column) specimens.

(A) PC1 vs. PC2 including only undistorted Diictodon specimens. (B) PC1 vs. PC2 including deformed Diictodon specimens. (C) PC1 vs. PC3 including only undistorted Diictodon specimens. (D) PC1 vs. PC3 including deformed Diictodon specimens. (E) PC1 vs. PC4 including only undistorted Diictodon specimens. (F) PC1 vs. PC4 including deformed Diictodon specimens. 

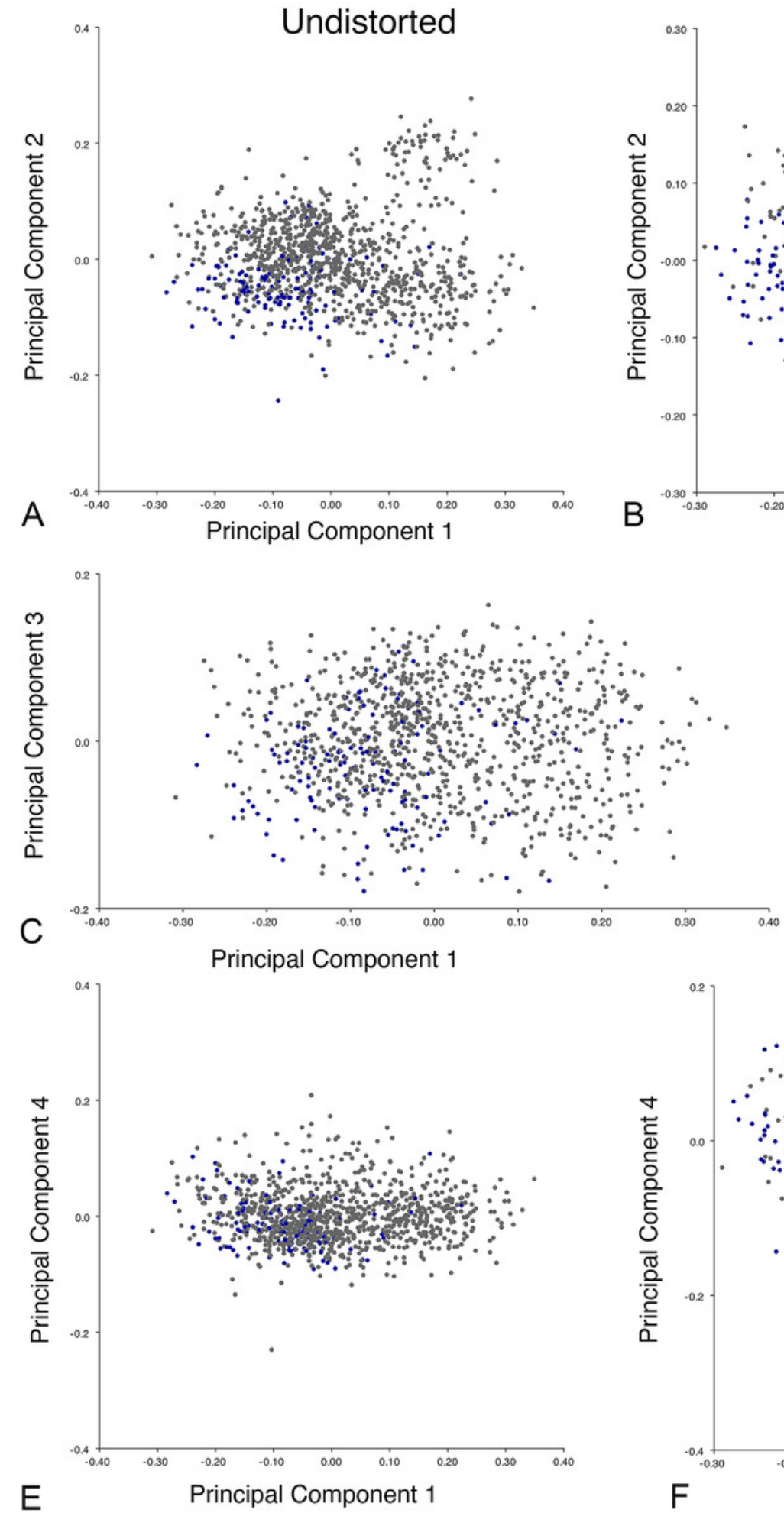
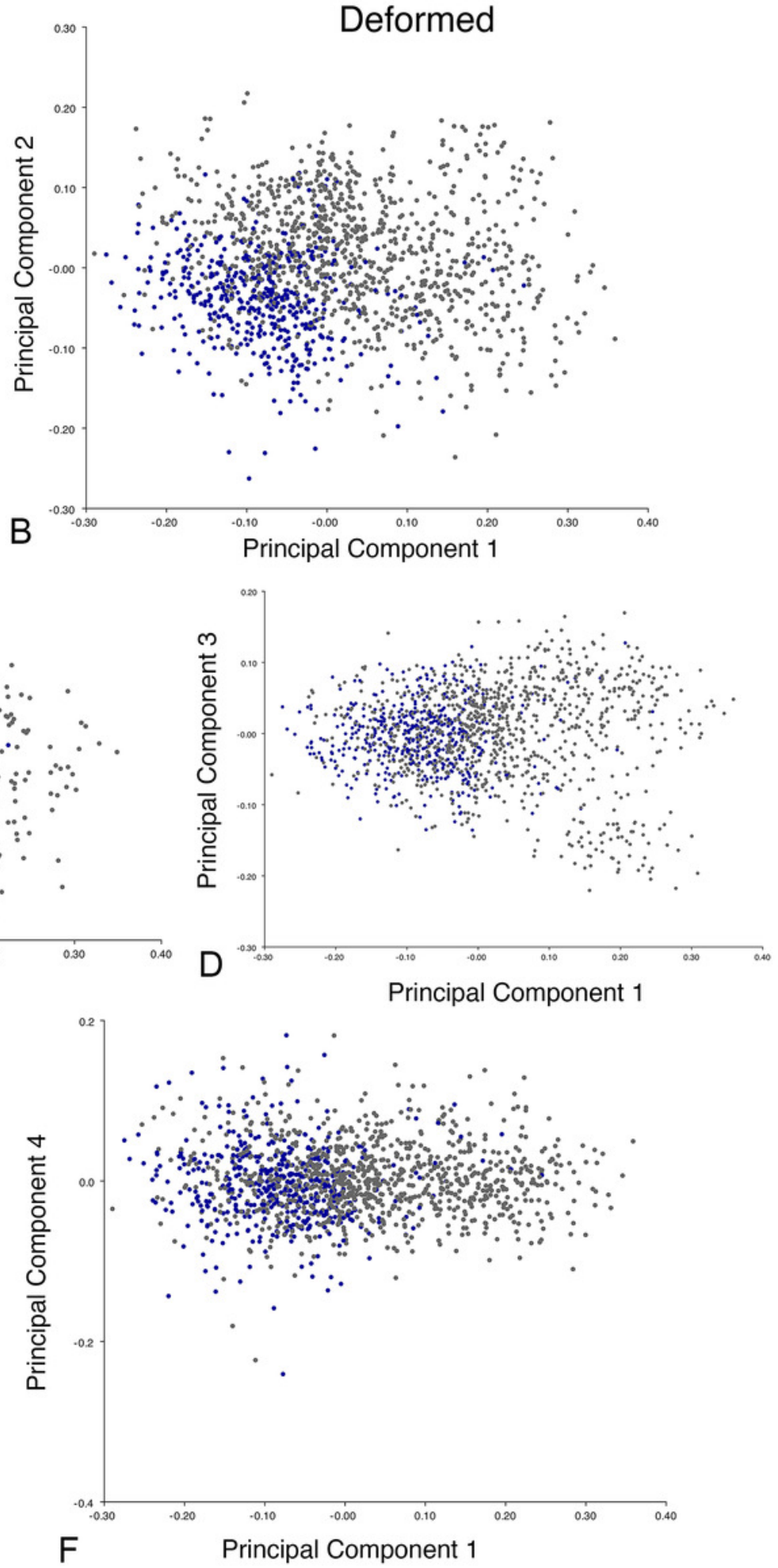